\title{
The effect of consolidation on undrained behaviour of granular materials: experiment and DEM simulation
}

1 Md. Mizanur Rahman BSc, PhD, MASCE, MIEAust, FIEB Associate Professor in Geotechnical Engineering, School of Natural and Built Environments, University of South Australia, Adelaide, South Australia, Australia; and Research Strand Leader, Natural and Built Environments Research Centre, University of South Australia, Adelaide, South Australia, Australia (corresponding author: mizanur.rahman@unisa.edu.au) (Orcid:0000-0002-0638-4055)
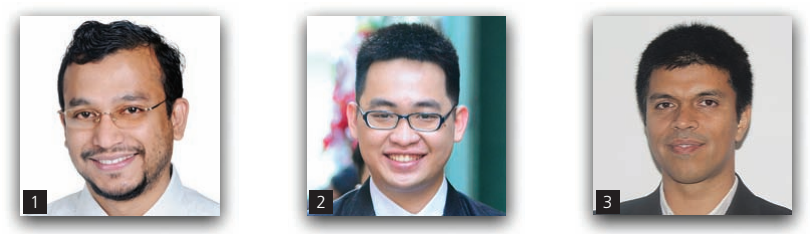

2 Hoang Bao Khoi Nguyen BEng, PhD

Research Associate, School of Natural and Built Environments, University of South Australia, Adelaide, South Australia, Australia (Orcid:0000-0001-7280-9472)

3. Abu Taher Md Zillur Rabbi PhD

Research Associate, School of Natural and Built Environments, University of South Australia, Adelaide, South Australia, Australia (Orcid:0000-0002-7065-5606)

The characteristic features of undrained responses of granular materials, for example, stress ratio at instability ( $\left.\eta_{1 \mathrm{~S}}\right)$ and phase transformation ( $\eta_{\mathrm{PT}}$ ) states and the critical state (CS) behaviour, are often influenced by the consolidation history. However, there are limited studies in the literature, and a consensus has not yet been reached. This study combined the triaxial test of yellow silty sand and the three-dimensional discrete element method (DEM) simulation of ellipsoid particles under a triaxial condition to evaluate the effect of isotropic and $K_{0}$ consolidations. Triaxial test data formed non-unique CS lines (CSLs) in the e-log $\left(p^{\prime}\right)$ space for isotropic and $K_{0}$ tests, whereas the CSL was unique for DEM simulations; where $e$ and $p^{\prime}$ are the void ratio and mean effective stress, respectively. The micromechanical quantities, coordination number $\left(C_{\mathrm{N}}\right)$ and fabric anisotropy $\left(F_{\mathrm{vM}}\right)$ at the $\mathrm{CS}$, also showed a unique relation with $p^{\prime}$. The characteristic features, $\eta_{\mathrm{IS}}$ and $\eta_{\mathrm{PT}}$, showed good correlation with the state parameter $(\psi)$ and the density indices. It was found that the $\eta_{1 \mathrm{~s}}$ decreased with $\psi_{r}$ and the correlation was dependent on consolidation type. The micromechanical analysis suggested that $F_{\mathrm{vM}}$ is a better parameter than $C_{\mathrm{N}}$ to characterise the macromechanical behaviour. This study unambiguously supports the applicability of CS theory and provides insights into micromechanics of granular materials.

$\begin{array}{ll}\text { Notation } & \\ B & \text { Skempton's pore pressure parameter } \\ C & \text { number of particle contacts } \\ C_{\mathrm{N}} & \text { coordination number } \\ D_{\mathrm{I}} & \text { densification index } \\ D_{\mathrm{r}} & \text { relative density } \\ d & \text { diameter of particle } \\ \mathrm{d} & \text { incremental rate } \\ \mathrm{e} & \text { void ratio } \\ e_{\text {low }} & \text { void ratio on lower consolidation line } \\ e_{\mathrm{max}} & \text { maximum void ratio } \\ e_{\min } & \text { minimum void ratio } \\ e_{\mathrm{up}} & \text { void ratio on upper consolidation line } \\ \boldsymbol{F} & \text { fabric tensor } \\ F_{i j} & \text { scalar value of fabric tensor } \\ F_{\mathrm{vM}} & \text { von Mises (deviatoric) fabric } \\ I & \text { inertial number } \\ J_{1}, J_{2} \text { and } J_{3} & \text { invariants of } \boldsymbol{s} \boldsymbol{F} \\ K & \text { principal stress ratio }\left(\sigma_{3}^{\prime} / \sigma_{1}^{\prime}\right) \\ K_{0} & \text { principal stress ratio 'at rest' }\end{array}$

$\begin{array}{ll}M & \text { critical state stress ratio }\left(q / p^{\prime}\right) \\ N & \text { number of particles } \\ N_{\mathrm{O}} & \text { number of particles having no contact } \\ N_{1} & \text { number of particles having only one contact } \\ \boldsymbol{n}^{k} & \text { direction (unit vector) of the } k \text { th contact } \\ p^{\prime} & \text { mean effective confining stress } \\ q & \text { deviatoric stress } \\ \boldsymbol{s} \boldsymbol{F} & \text { deviatoric fabric tensor } \\ s F_{i j} & \text { scalar value of fabric tensor } \\ u_{\mathrm{F}} & \text { flow potential } \\ V & \text { volume } \\ Z_{\mathrm{m}} & \text { mechanical coordination number } \\ \Delta & \text { rate of change } \\ \Delta u & \text { pore water pressure } \\ \delta_{i j} & \text { Kronecker delta } \\ \dot{\varepsilon} & \text { shear strain rate } \\ \varepsilon_{\mathrm{q}} & \text { deviatoric strain } \\ \varepsilon_{\mathrm{v}} & \text { volumetric strain } \\ \varepsilon_{1}=\varepsilon_{11} & \text { axial strain } \\ \varepsilon_{2}=\varepsilon_{22} & \text { lateral strain }\end{array}$


The effect of consolidation on undrained

behaviour of granular materials:

experiment and DEM simulation

Rahman, Nguyen and Rabbi

$\begin{array}{ll}\varepsilon_{3}=\varepsilon_{33} & \text { lateral strain } \\ \eta & \text { stress ratio } \\ \theta_{\mathrm{m}} & \text { mobilised friction angle } \\ \rho_{\mathrm{g}} & \text { particle density } \\ \boldsymbol{\sigma} & \text { stress tensor } \\ \sigma_{1} & \text { major total stress } \\ \sigma_{2} & \text { minor total stress } \\ \sigma_{3} & \text { minor total stress } \\ \sigma_{1}^{\prime}=\sigma_{11}^{\prime} & \text { major effective stress } \\ \sigma_{2}^{\prime}=\sigma_{22}^{\prime} & \text { minor effective stress } \\ \sigma_{3}^{\prime}=\sigma_{33}^{\prime} & \text { minor effective stress } \\ \chi_{1} & \text { average force imbalance divided by the average } \\ & \text { contact force } \\ \chi_{2} & \text { average moment imbalance by the average } \\ \psi & \text { contact force and particle radius } \\ & \text { state parameter }\end{array}$

\section{Subscripts}

0 start of shearing

CS feature at critical state

IS feature at instability

peak feature at peak deviatoric stress

PT feature at phase transformation state

\section{Introduction}

The undrained behaviours of granular materials are frequently classified as non-flow (NF), flow (F) and limited flow (LF) in the literature (Alarcon-Guzman et al., 1988; Bobei and Lo, 2005;
Mohamad and Dobry, 1986); schematic diagrams of these behaviours are shown in Figures 1(a) and 1(b). Loose specimens exhibit $F$ behaviour where the deviatoric stress $(q)$ quickly attains an initial peak $\left(q_{\text {peak }}\right)$, represented by the yellow circles in Figures 1(a) and 1(b), and then $q$ softens until reaching an equilibrium at the critical state (CS); where $q=\left(\sigma_{1}^{\prime}-\sigma_{3}^{\prime}\right)$, and $\sigma_{1}^{\prime}$ and $\sigma_{3}^{\prime}$ are the principal effective stresses in the major and minor directions. For the $\mathrm{F}$ behaviour, the pore water pressure $(\Delta u)$ increases throughout shearing and reaches a peak $\Delta u$, where $\mathrm{d} \Delta u=0$ at CS (see Figure 1(c)). When $\Delta u$ becomes equal to the value of initial $p^{\prime}$, then it is referred to as complete liquefaction; otherwise, it is simply referred to as liquefaction hereafter, where $p^{\prime}$ is the mean effective stress and equal to $\left(\sigma_{1}^{\prime}+2 \sigma_{3}^{\prime}\right) / 3$. Medium dense specimens exhibit LF behaviour, where $q$ hardens after initial softening. The strain softening as a form of $\mathrm{d} q / \mathrm{d} \varepsilon_{\mathrm{q}}<0$ in both the $\mathrm{F}$ and LF behaviours is the triggering of static liquefaction, where $\varepsilon_{\mathrm{q}}$ is the deviatoric strain. The triggering of static liquefaction can be presented by the instability stress ratio $\left(\eta_{\mathrm{IS}}=q / p^{\prime}\right)$ in the $q-p^{\prime}$ space, as shown in Figure 1(b). Dense specimens exhibit NF behaviour, where $q$ hardens until reaching the CS. In the case of LF and NF behaviours, $\Delta u$ initially increases (contractive) to a local peak and then decreases (dilative). The transition between contractive and dilative states - that is, the phase transformation (PT) state in LF and NF behaviours - occurs at the 'knee' of the effective stress path (ESP) in $q-p^{\prime}$ space or the local peak $\Delta u$ in $\Delta u-\varepsilon_{\mathrm{q}}$ space, represented by the yellow diamonds in Figure 1 (Ishihara et al., 1975). Therefore, both $\eta_{\text {IS }}$ and PT are important characteristic features of undrained behaviour. The anchor concept of the critical state soil mechanics (CSSM)

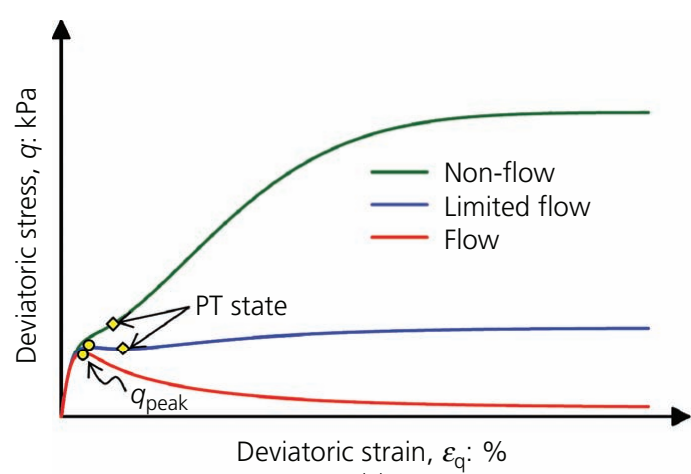

(a)

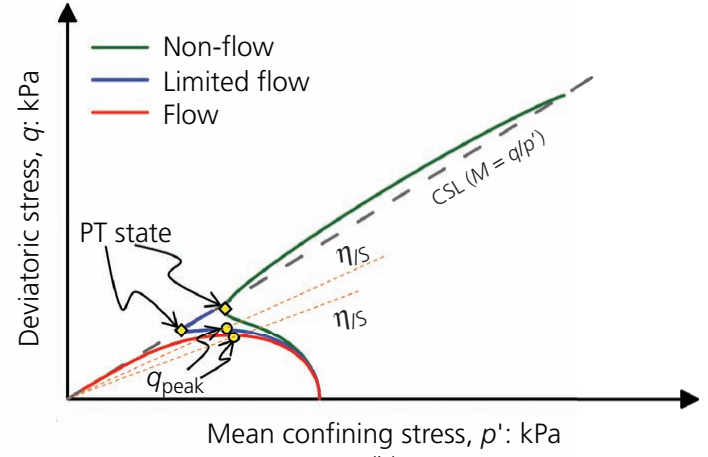

(b)

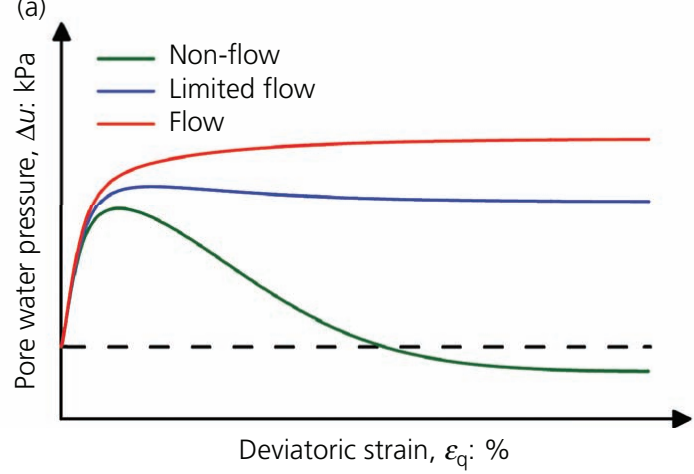

(c)

Figure 1. Undrained responses of sands in the (a) $q-\varepsilon_{\mathrm{q}}$, (b) $q-p^{\prime}$ and (c) $\Delta u-\varepsilon_{\mathrm{q}}$ spaces. PT, phase transmission; CSL, critical state line 
framework is that the CS data points from these tests form a line in the $e-\log \left(p^{\prime}\right)$ space, which is commonly known as critical state line (CSL). The CSL is the reference line to define the state of a soil. The characteristic features - for example, $\eta_{\mathrm{IS}}$ and PT - are assumed to be dependent on soil states with respect to CSL. Therefore, simple functional forms are suggested for such states with respect to CSL that can be measured from a laboratory triaxial test or estimated from a field test (Chu et al., 2015; Shuttle and Jefferies, 2016) and also incorporated into constitutive modelling (Imam et al., 2002; Ishihara, 1993; Jefferies et al., 2015; Li and Dafalias, 2000).

The CSSM framework is elegant and more widely evaluated with experimental data for granular materials after isotropic consolidation than $K_{0}$ consolidation. However, there are experimental evidences that the consolidation history may affect the undrained response of sand and its corresponding CS behaviour. For instance, Finno and Rechenmacher (2003) reported that the location of CSL is affected by the consolidation history and initial state (i.e. before consolidation) of sand. The study of Fourie and Tshabalala (2005) found different CSLs for isotropically and $K_{0}$-consolidated specimens. They also found that $\eta_{\text {IS }}$ values of $K_{0}$ consolidation were higher than those of isotropic consolidation. However, many other studies found a unique CSL for a soil regardless of consolidation condition (Kato et al., 2001). The uniqueness or non-uniqueness of CSL for different consolidations is a significant consideration for establishing the CSSM framework and its application for engineering practice. Due to the disagreement in literature, the effect of consolidation on the CS behaviour of soil requires further investigation.

Recognising the limitations of element tests under laboratory conditions, such as the sensitivity of monitoring transducers, disturbance/non-uniformity of specimens and shear band formation, the discrete-element method (DEM) has been gaining popularity for the qualitative understanding of soil behaviour under the CSSM framework. DEM does not have the same limitations as laboratory experimentation and also allows the understanding of particle interactions. There are published studies on CS behaviour of the assembly of two-dimensional circular and three-dimensional (3D) spherical particles (Huang et al., 2014; Kuhn, 2016; Sitharam and Vinod, 2009; Yan and Dong, 2011; Zhao and Guo, 2013); however, there is no detailed study on the effect of isotropic and $K_{0}$ consolidations on undrained response, its characteristic features and CS behaviour.

Therefore, the objectives of this study are to $(a)$ evaluate the effect of isotropic and $K_{0}$ consolidations on undrained behaviour of saturated yellow silty (YS) sand and DEM simulations of 3D cubical assembly of ellipsoid particles under triaxial condition. This study did not attempt to simulate undrained behaviour of YS sand; rather, it attempted to evaluate undrained characteristic features - for example, $\eta_{\mathrm{IS}}$, PT and CS - of granular materials that were observed for both laboratory triaxial test and DEM simulation. It is envisaged that such comparative evaluation between laboratory test and DEM will lead to the better understanding of the fabric-dependent behaviour of granular materials - for example, Yoshimine et al. (1998) and Li and Dafalias (2012); (b) evaluate unique/non-unique CSLs for isotropic and $K_{0}$ consolidations; $(c)$ evaluate the correlation for the undrained characteristic features - for example, PT state and $\eta_{\mathrm{IS}}$ - with state indices; and $(d)$ evaluate the correlation for micromechanics measures such as particle contact and fabric anisotropy with state indices. This study enhances the understanding of the fundamental basis of the relationship between macro- or micromechanical responses and state indices of cohesionless granular materials.

\section{Materials and methodologies}

This study is composed of the triaxial testing of YS sand and the discrete element simulation of 3D ellipsoid particles. The physical properties of YS sand and the numerical properties of ellipsoid particles as well as laboratory testing and numerical simulation methodologies are explained below.

\section{YS sand and 3D ellipsoid particles}

The YS sand, from South Australia, was used in this study. It is poorly graded and contained about $10 \%$ fines (poorly graded silty sand (SP-SM) according to the Unified Soil Classification System (USCS)), where fines are particles that have sizes smaller than $0.075 \mathrm{~mm}$. The minimum and maximum void ratios are 0.423 $\left(1.86 \mathrm{~g} / \mathrm{cm}^{3}\right)$ and $0.892\left(1.40 \mathrm{~g} / \mathrm{cm}^{3}\right)$, respectively, according to ASTM D 4253 (ASTM, 2016) and ASTM D 698 (ASTM, 2017) methods, respectively. The clean sand is uniform and subrounded in nature. The fines were obtained by wet sieving of YS sand and classified as low plastic silt (ML) according to USCS which have a liquid limit (LL) and plasticity index (PI) of $40 \cdot 0 \%$ and $9 \cdot 3 \%$, respectively.

The reason for using 3D elliptical particles is to capture an essence of angularity and reduce the computational demand as required for clustered particles. The grain size distribution curve of YS sand and 3D ellipsoids with their distribution of eccentricity - that is, height to width ratios - are shown in Figure 2. It is noted that the sizes and shapes of individual grains and specimens for laboratory testing and DEM simulation were

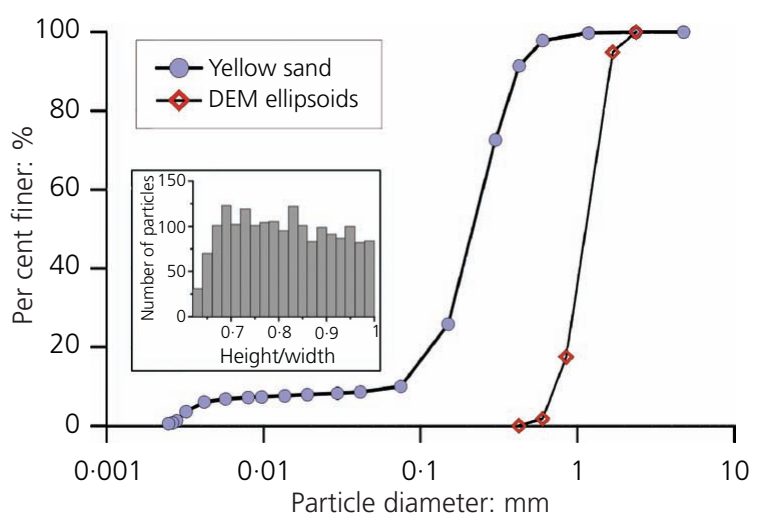

Figure 2. Grain size distribution for YS sands and ellipsoid particles for DEM 
different. Ellipsoid particles in DEM were larger and smoother than natural YS sand particles. A smaller and cubical specimen was used for DEM simulation, whereas a large cylindrical specimen was used in laboratory triaxial testing. These variations are commonly adopted for DEM simulations for simplicity and less computational demand as reported in many studies ( $\mathrm{Gu}$ et al., 2014; Huang et al., 2014). As this study did not attempt to simulate YS sand behaviour with DEM, it rather attempted to evaluate the characteristic features that was reported for both laboratory triaxial test and DEM simulations, and the objective of this study was not significantly influenced by these variations. The DEM particles were assigned a normal contact stiffness of $10^{8} \mathrm{~N} / \mathrm{m}$, ratio of tangential to normal contact stiffness of 1 , coefficient of friction at particle contacts of 0.5 and the coefficient of (rotational and translational) body damping of $0 \cdot 05$.

\section{Laboratory triaxial testing}

\section{Specimen preparation method}

Different specimen preparation methods have been used in the literature such as air pluviation, water sedimentation and moist tamping for triaxial testing. Each method offers different advantages in resembling certain field conditions and fabrics. The moist tamping method provides two advantages for this study: $(a)$ it produces very loose specimen suitable for liquefaction studies (Yamamuro and Lade, 1997) and (b) it reduces segregation of fines particles (Baki et al., 2012; Ladd, 1978; Rahman, 2009), which was a concern for YS sand. Therefore, a modified moist tamping method was adopted in this study (Bobei et al., 2009; Lo et al., 2010). A moist tamped specimen provides an initial soil fabric more representative of sandy deposits placed on land by end tipping, such as embankment fill or colluvium (Rahman et al., 2014a).

A $100 \mathrm{~mm}$ dia. and $100 \mathrm{~mm}$ high split mould of was placed over the enlarged bottom platen with free end, and a small vacuum of approximately $-10 \mathrm{kPa}$ was applied to hold the membrane inside this mould. The moist sand was tamped in ten layers to increase the homogeneity and reduce the variation in local density between neighbouring layers. The thickness of each layer was controlled using a height-controlled tamping rod. Free ends with enlarged platen reduce end restraint to a minimal value as verified in a number of studies on silt size to sand size materials (Bobei et al., 2009; Lo and Wardani, 2002; Lo et al., 2010). Figure 3(a) shows a specimen just after dismantling the split mould. Note that specimens with height-to-diameter ratio were unity, because it $(a)$ was easier to prepare in terms of controlling uniformity of initial density and (b) minimised the likelihood and extent of specimen tilting during shearing. This approach has been well documented in literatures (Baki et al., 2014; Bobei et al., 2013; Chu et al., 1993; Rahman et al., 2008; Yamamuro and Lade, 1998; Zhang et al., 2018).

\section{Saturation method}

Carbon dioxide $\left(\mathrm{CO}_{2}\right)$ was pumped into the specimen through the bottom platen for at least $10 \mathrm{~min}$ before the dismantlement of the split mould. Then saturation was performed in two stages: vacuum flushing and back pressure saturation. In stage 1, the specimen was flushed under the vacuum of $-20 \mathrm{kPa}$ overnight with de-aired water, and then in stage 2, a back pressure of $400 \mathrm{kPa}$ was applied maintaining a $p^{\prime}$ of $20 \mathrm{kPa}$. The specimen was left to rest with the back pressure for approximately $5 \mathrm{~h}$ to help dissolve any remaining air in the water. In most cases, a Skempton's $B$ value of 0.98 or higher was achieved in each test to ensure adequate saturation.

\section{Isotropic consolidation module}

The consolidation was conducted using a computer control module. During isotropic consolidation, the module increased cell pressure to the target cell pressure at specified intervals while allowing pore-water drainage to keep the pore-water pressure (back pressure) constant. While increasing isotropic cell pressure

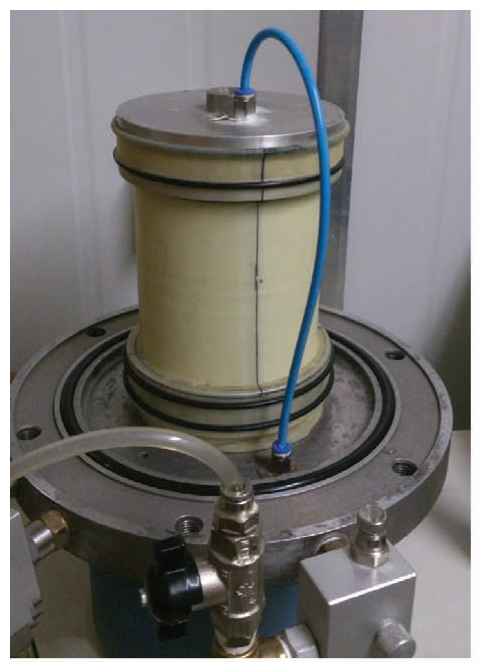

(a)

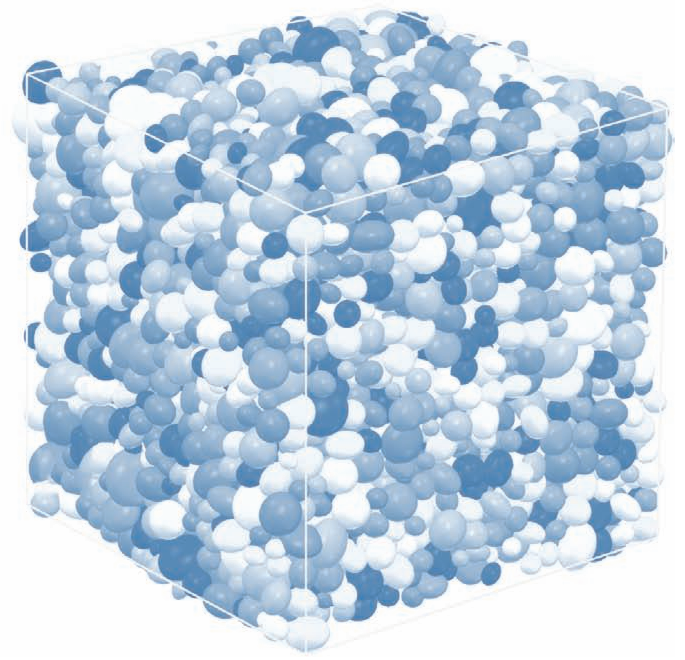

(b)

Figure 3. Specimens for this study: (a) YS sand specimen and (b) DEM assembly 
( $\sigma_{1}=\sigma_{2}=\sigma_{3}$ ), the $q$ was maintained constant to the user-defined value, usually $q=1 \mathrm{kPa}$, in the bedding control. Although the bedding control was not necessary for isotropic consolidation, it was maintained for consistency with other testing - for example, $K_{0}$ consolidation and extension test. The digital pressure volume controller (DPVC) was used to measure the volume change during isotropic consolidation as well as keeping back pressure constant. Independent pressure transducers were used just outside the cell to check pore-water pressure equilibrium.

\section{$K_{0}$ consolidation module}

First, a constant axial strain rate was applied, producing an increase in the effective vertical stress $\left(\sigma_{1}^{\prime}\right)$ up to the target value. For the applied vertical strain, zero radial strain was enforced by the DPVC in the manner described by Menzies (1988). In this module, a feedback system calculated the change of specimen volume $(\Delta v)$ equal to the axial deformation increment multiplied by the current cross-sectional area of the specimen for a time step (default: $6 \mathrm{~s}$ ). The time step was adjustable depending on the material response. The feedback system then commanded the DPVC to extract the volume of $\Delta v$ to maintain zero radial strain - that is, $\varepsilon_{v}=\varepsilon_{1}$ as shown in the following.

1. $\varepsilon_{\mathrm{v}}=\varepsilon_{1}+2 \varepsilon_{3} \rightarrow \varepsilon_{\mathrm{v}}=\varepsilon_{1} \quad$ when $\varepsilon_{3}=0$

where $\varepsilon_{v}$ is the volumetric strain. The extraction of volume causes a subsequent reduction to the pore pressure $u$ (back pressure). To avoid the potential problem that a lower pore pressure may cause partial desaturation, the program commands the cell pressure regulator to increase the cell pressure by the drop in pore pressure. As change in pore pressure, $\Delta u=B \Delta_{3}$, where $B$ is Skempton's pore pressure parameter, and assuming that the specimen is nearly saturated $(B \approx 1)$, this action will restore the back pressure to the desired level. If $B$ is somewhat less than 1 , then there may be a lag in the restoration of the back pressure.

Once the consolidation is completed, the program has two exit modes, either 'freeze stress' or 'freeze strain'. In the freeze stress mode, the control program keeps cell pressure, deviator stress and back pressure at their final values. Granting that pore pressures may still be equalising to some degree, and that the specimen may creep a small amount, the final $K_{0}$ condition may be compromised if the specimen is held in this state for a protracted length of time. On the other hand, in the freeze strain mode, the ram is stopped at the exit of $K_{0}$ consolidation - that is, axial strain is fixed, and the DPVC ceases volume change and reverts to pore pressure measurement. The cell pressure and pore pressure remain constant, but the deviator stress may keep changing slightly, depending on specimen stiffness. In this study, the freeze stress exit mode was used for all the tests.

\section{Undrained shearing}

The axial force was applied to the specimens at a constant deformation rate, and the cell pressure was kept constant at the initial value. In the undrained condition, the DPVC did not allow volume change, but the change of pore water pressure was measured.

\section{DEM simulation of triaxial testing}

The DEM software called Oval, developed by Kuhn (2006), was used for this study. The 3D ellipsoids assembly of cubical specimen under triaxial condition was simulated. Two methods were employed for preparing ellipsoid assemblies: staged isotropic consolidation and particle elimination (discussed later). A linear contact model and periodic boundary condition were considered in this study.

\section{Staged isotropic consolidation}

A staged isotropic consolidation approach, similar to that of Guo and Zhao (2013), was employed to achieve different densities. A set of specimens with a large number of particles (particle number $N$ varied from 4350 to 5400 ) with the same grain size distribution was randomly generated in cubical $3 \mathrm{D}$ space. It is noted that there was no contact between particles at the beginning of this stage. The particles were then assigned with varying coefficients of friction at particle contacts $(0-0 \cdot 50)$ and $3 \mathrm{D}$ isotropic stress $\left(\sigma_{1}^{\prime}=\sigma_{2}^{\prime}=\sigma_{3}^{\prime}\right)$ up to $20 \mathrm{kPa}$ was applied to achieve a desired void ratio. A higher coefficient of friction was used to generate a loose assembly. Note that after this stage, the coefficient of friction of all simulations was $0 \cdot 50$.

\section{Particle elimination}

The staged isotropic consolidation introduces different stress histories for different coefficients of friction at particle contacts during consolidation of up to $20 \mathrm{kPa}$. To avoid this, a new specimen preparation method was sought, and the particle elimination method was developed. In this method, a reference specimen was firstly achieved with ellipsoid with a very high density at $p^{\prime}$ of $20 \mathrm{kPa}$ by the staged isotropic consolidation. A MatLab code was developed to eliminate some ellipsoid particles from a dense specimen in such a way that the grain size distribution and particle orientation remained the same. This is discussed by Nguyen et al. (2017). An example of ellipsoid assembly is shown in Figure 3(b). The smaller specimen size for this study was approximately $9.33 \times 9.33 \times 9.33 \mathrm{~mm}^{3}$. The equivalence of undrained behaviour of specimens prepared by these two methods was observed and discussed by Nguyen et al. (2017).

\section{Numerical challenges in DEM}

A representative elementary volume (REV), which is the smallest volume that can yield a representative value of the whole, is important for numerical simulation. To achieve an REV condition in DEM simulations, micromechanical measures, such as inertial number $(I)$, pseudostatic measures and specimen size, were examined in this study.

The quasi-static conditions of the DEM simulations were checked and maintained by analysing the inertial number $(I)$, which is given by the following equation.

2. $I=\dot{\varepsilon} d_{i} \sqrt{\rho_{\mathrm{g}} / p^{\prime}}$ 
where $\dot{\varepsilon}$ is shear strain rate $(1 / \mathrm{s}), d$ is the particle diameter $(\mathrm{m}), p^{\prime}$ is the mean stress $(\mathrm{kPa})$, and $\rho_{\mathrm{g}}$ is the particle density $\left(\mathrm{kg} / \mathrm{m}^{3}\right)$. The particle density $\left(\rho_{\mathrm{g}}\right)$ was $9.766 \times 10^{8} \mathrm{~kg} / \mathrm{m}^{3}$, which is approximately $3.69 \times 10^{5}$ times larger than $2650 \mathrm{~kg} / \mathrm{m}^{3}$ for real geomaterial as reported by Perez et al. (2016). To optimise the simulation time, the particle density was scaled up in the literature, and notably, Thornton (2000) used a scale-up factor of $10^{12}$. A similar scale-up approach was also observed by $\mathrm{Ng}$ (2006). The strain rate of $0.00001 \%$ per time step was found as suitable for all DEM simulations (Nguyen and Rahman, 2017; Nguyen et al., 2015). The calculated $I$ values for all simulations in this study were much smaller than the recommended value of 0.003 for quasi-static conditions (da Cruz et al., 2005).

Two variables, $\chi_{1}$ and $\chi_{2}$, were also checked to determine the numerical stability of the simulation. $\chi_{1}$ is the average force imbalance on a particle divided by the average magnitude of a contact force. $\chi_{2}$ is the average moment imbalance on a particle divided by both the average magnitude of a contact force and the average particle radius. For the applied strain rate, the highest values of $\chi_{1}$ and $\chi_{2}$ were below the recommended value of 0.005 (Kuhn, 2006) and considered that simulations were quasi-static.

\section{Controlling module in DEM simulation}

The Oval software allows a flexible stress or strain control triaxial simulation scheme by a six-digit input variable 'icontr', which represents the components of three principals in 11, 22 and 33 directions, and three shear 12, 13 and 23 directions. It should be noted that there are nine directions (i.e. three principal and six shear directions). However, the components in the directions 12 and 21,13 and 31,23 and 32 have the same magnitude but opposite direction. The different conditions in DEM simulations were achieved by adjusting these six components. The details are presented in the following.

- Isotropic consolidation. The rates of change of principal stresses are the same - that is, $\mathrm{d} \sigma_{11}^{\prime}=\mathrm{d} \sigma_{22}^{\prime}=\mathrm{d} \sigma_{33}^{\prime}$. Note that single digit notations for principal stresses - that is, 1,2 and 3 - were used in subscript when explaining the triaxial testing.

- $K_{0}$ consolidation. For an applied rate of major principal stress, the lateral strains are maintained constant or no lateral deformation - that is, $\mathrm{d} \varepsilon_{22}=\mathrm{d} \varepsilon_{33}=0$.

- Undrained shearing. For an applied axial strain rate, the volume of the assembly is maintained constant by adjusting the lateral strains. There was no pore water pressure development $(\Delta u)$ during DEM simulation. However, it was determined by the difference between $p^{\prime}$ for drained and undrained paths as explained by Sitharam et al. (2008) and Nguyen et al. (2018).

\section{Micromechanical quantities}

DEM allows the examination of particle interactions or contacts to establish links with the macroresponse of granular materials. Therefore, the coordination number $\left(C_{\mathrm{N}}\right)$ and mechanical coordination number $\left(Z_{\mathrm{m}}\right)$, as defined by Rothenburg and Bathurst
(1989) and Thornton (2000), respectively, were used in this study. They can be mathematically expressed as follows.

3a. $C_{\mathrm{N}}=2 C / N$

3b. $Z_{\mathrm{m}}=\left(2 C-N_{1}\right) /\left(N-N_{0}-N_{1}\right)$

where $C_{\mathrm{N}}$ is the coordination number, $C$ is the total number of contacts, $N$ is the number of particles, $N_{0}$ is the number of particles having no contact and $N_{1}$ is the number of particles having only one contact in the specimen. Note that previous studies showed that $Z_{\mathrm{m}}>C_{\mathrm{N}}$, and their evolution paths are parallel during undrained shearing (Nguyen et al., 2017). Therefore, $C_{\mathrm{N}}$, instead of $Z_{\mathrm{m}}$, is used to synthesise the simulation data.

The structural anisotropy can be determined by the fabric tensor $\boldsymbol{F}$, which was firstly introduced by Satake (1982) and expressed in the following equation.

4.

$$
\boldsymbol{F}=F_{i j}=\frac{1}{N} \sum_{k=1}^{N} \boldsymbol{n}_{i}^{k} \boldsymbol{n}_{j}^{k}=\left[\begin{array}{lll}
F_{11} & F_{12} & F_{13} \\
F_{21} & F_{22} & F_{23} \\
F_{31} & F_{32} & F_{33}
\end{array}\right]
$$

where $\boldsymbol{n}^{k}$ is the direction (unit vector) of the $k$ th contact and $N$ is the number of contacts in the specimen. The bold character (e.g. $\boldsymbol{F}$ ) indicates the tensor, whereas the italic character (e.g. $F_{i j}$ ) indicates the scalar value of the tensor. $F_{11}, F_{22}$ and $F_{33}$ are the fabric in the principal directions $(i=j)$, and $F_{12}, F_{13}, F_{21}, F_{23}, F_{31}$ and $F_{32}$ are the fabric in the shear directions $(i \neq j)$. As mentioned earlier, the scalar values of shear components in opposite direction are equal that is, $F_{12}=F_{21}, F_{13}=F_{31}$ and $F_{23}=F_{32}$. The fabric tensor can be formulated based on the theory of Cauchy stress tensor $(\boldsymbol{\sigma})$, and the deviatoric fabric tensor $(\boldsymbol{s} \boldsymbol{F})$ can be expressed as

5. $\boldsymbol{s} \boldsymbol{F}=s F_{i j}=F_{i j}-\frac{F_{k k}}{3} \delta_{i j}$

where

6a. $\quad F_{k k}=\operatorname{tr}(\boldsymbol{F})=F_{11}+F_{22}+F_{33}$

6b. $\quad \delta_{i j}= \begin{cases}1 & \text { if } i=j \\ 0 & \text { if } i \neq j\end{cases}$

where the notation ' $\operatorname{tr}(\ldots)$ ' indicates the trace of a tensor and $\delta_{i j}$ is Kronecker delta. $\boldsymbol{s} \boldsymbol{F}$ has a set of invariants - for example, $J_{1}, J_{2}$ and $J_{3}-$ and its characteristic equation can be written as 
7. $\left|s F_{i j}-\lambda \delta_{i j}\right|=-\lambda^{3}+J_{1} \lambda^{2}-J_{2} \lambda+J_{3}=0$

where $\lambda$ is the constant of proportionality. The invariants of $\boldsymbol{s} \boldsymbol{F}$ can be defined as

8a. $J_{1}=\operatorname{tr}(\boldsymbol{s} \boldsymbol{F})=0$

$$
\begin{aligned}
& J_{2}= \frac{1}{2} \operatorname{tr}\left(\boldsymbol{s} \boldsymbol{F}^{2}\right) \\
&= \frac{1}{6}\left[\left(F_{11}-F_{22}\right)^{2}+\left(F_{11}-F_{33}\right)^{2}+\left(F_{22}-F_{33}\right)^{2}\right] \\
& \text { 8b. } \quad+F_{12}^{2}+F_{13}^{2}+F_{23}^{2}
\end{aligned}
$$

8c. $J_{2}=\frac{1}{3} \operatorname{tr}\left(\mathbf{s} \boldsymbol{F}^{3}\right)$

Based on von Mises stress yield criterion, a similar scalar quantity of equivalent deviatoric fabric - that is, von Mises fabric $\left(F_{\mathrm{vM}}\right)-$ can be defined as

9. $\quad F_{\mathrm{vM}}=\sqrt{3 J_{2}}$

\section{Comparison of isotropic and $K_{0}$ consolidation: triaxial test and DEM simulation}

Figure 4(a) shows four pairs of isotropic and $K_{0}$ consolidation paths for the same preconsolidation $e$ for both triaxial and DEM simulations in the $e-\log \left(p^{\prime}\right)$ space. Although the loose triaxial test pair (YS-CIU05 and $\mathrm{YS}-\mathrm{K}_{0} \mathrm{U} 13$ ) had approximately the same preconsolidation $e$ of $0 \cdot 670$, the $K_{0}$ consolidation path showed higher compression. Similarly, the dense triaxial test pair (YS-CIU15 and YS- $\mathrm{K}_{0} \mathrm{U} 08$ ) had approximately the same preconsolidation $e$ of $0 \cdot 590$, the $K_{0}$ consolidation path showed slightly higher compression. However, the difference of compressibility for isotropic and $K_{0}$ consolidations was higher for higher preconsolidation $e$. Similarly,

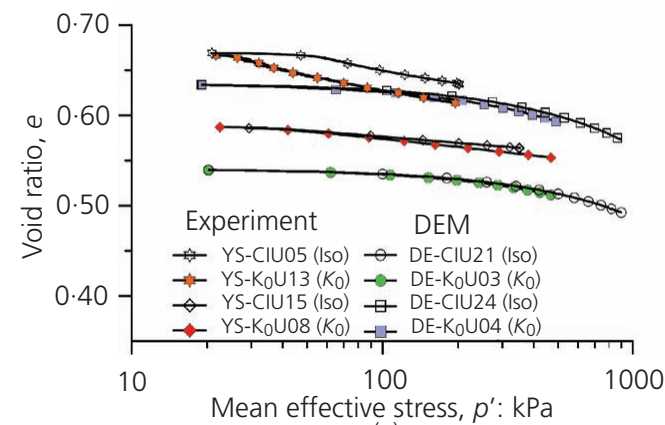

(a) the loose (DE-CIU24 and DE- $\mathrm{K}_{0} \mathrm{U} 04$ ) and dense (DE-CIU21 and $\mathrm{DE}-\mathrm{K}_{0} \mathrm{U} 03$ ) pairs from DEM simulations showed different compressibilities for different consolidation paths. The $K_{0}$ consolidation paths showed slightly higher compression than isotropic consolidation, which increases with $e$. The purpose of Figure 4 is not to compare quantitatively the results from experiments and DEM simulations, but to capture the change in compressibility for isotropic and $K_{0}$ consolidations and the trend of increasing compressibility with $e$ for YS sand and other experimental studies (Butterfield and Marchi, 2017; Wong et al., 2017). Figure 4(b) shows the stress ratio $\left(K=\sigma_{3}^{\prime} / \sigma_{1}^{\prime}\right)$ evolution paths of the triaxial tests and DEM simulations (presented in Figure 4(a)) in the $K-\sigma_{1}^{\prime}$ space. It shows that $K=1$ was maintained for isotropic consolidation; however, the $K$ quickly dropped from 1 at the early stage of $K_{0}$ consolidation (approximately $\sigma_{1}^{\prime}<100 \mathrm{kPa}$ ) and then gradually tends to reach a constant value at a higher stress level (approximately $\sigma_{1}^{\prime}=400 \mathrm{kPa}$ ). It seems that the constant $K$ - that is, $K_{0}$ value - is dependent on the preconsolidation $e$ of DEM simulation. For instance, the preconsolidation $e$ values of DE- $\mathrm{K}_{0} \mathrm{U} 03$ and $\mathrm{DE}-\mathrm{K}_{0} \mathrm{U} 04$ were 0.540 and 0.634 , respectively, and the loose specimen showed an early drop of $K$ at lower $\sigma_{1}^{\prime}$ than the dense specimen, but it achieved a higher $K_{0}$ than the dense specimen - that is, $K_{0}$ increases with $e$. Similarly, the loose triaxial specimen (YS$\mathrm{K}_{0} \mathrm{U} 13$ ) showed an early drop of $K$ at lower $\sigma_{1}^{\prime}$; however, the test was terminated at a smaller $\sigma_{1}^{\prime}$ (to maintain the same $p^{\prime}$ of YSCIU05) and could not confirm that $K_{0}$ increases with $e$. However, in general, it was found for triaxial tests that the value of $K_{0}$ increases with preconsolidation $e$. This observation differs from the widely used Jaky (1944) equation - that is, $K_{0}=1-\sin \theta_{\mathrm{m}}$, which suggests that $K_{0}$ only depends on the mobilised angle of internal friction $\left(\theta_{\mathrm{m}}\right)$.

The micromechanical quantities - that is, $C_{\mathrm{N}}$ and $F_{\mathrm{vM}}$ from the DEM simulations - also depicted the difference in consolidation history as shown in Figure 5. Starting at the same value, the $C_{\mathrm{N}}$ evolved to a much lower value under $K_{0}$ condition than the $C_{\mathrm{N}}$ under isotropic condition (Figure $5(\mathrm{a})$ ). Note that higher $C_{\mathrm{N}}$ implies stable state. Since $K_{0}$ has lower $C_{\mathrm{N}}$, it shows higher compressibility in Figure 4(a) than isotropic consolidation. Figure 5(b) shows that $F_{\mathrm{vM}}$ fluctuates around zero during isotropic condition. On the other hand, $F_{\mathrm{vM}}$ quickly increases at a low $\sigma_{1}^{\prime}$ for $K_{0}$ condition and then reaches

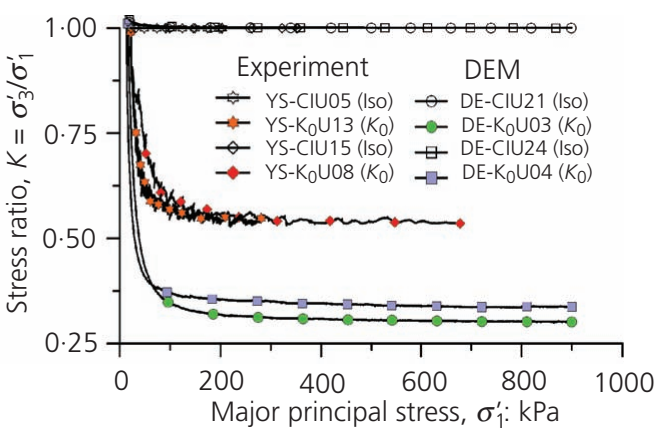

(b)

Figure 4. Isotropic and $K_{0}$ consolidation paths in triaxial test and DEM simulation: (a) in e-log( $\left.p^{\prime}\right)$ and (b) in $K-\sigma_{1}^{\prime}$ space 


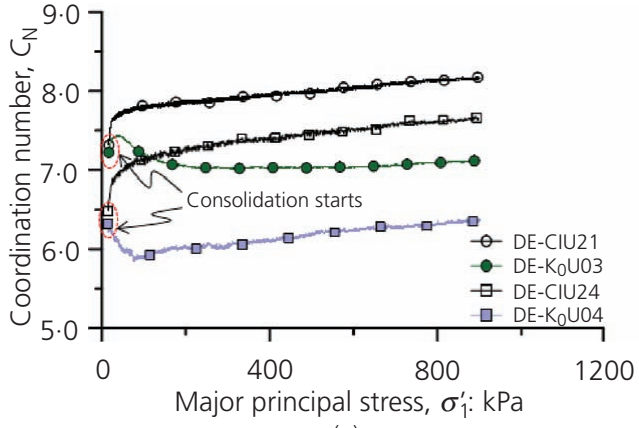

(a)

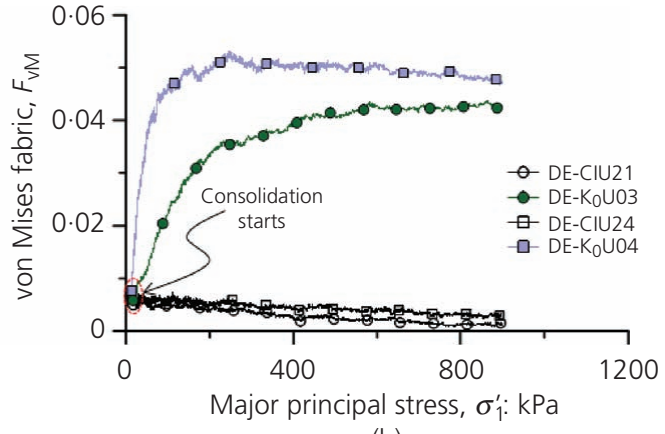

(b)

Figure 5. The evolution of micromechanical quantities during isotropic and $K_{0}$ consolidations: (a) in $C_{N}-\sigma_{1}^{\prime}$ space and (b) in $F_{\mathrm{vM}}-\sigma_{1}^{\prime}$ space

equilibrium at a higher $\sigma_{1}^{\prime}$. It is noted that micromechanical quantities - for example, $C_{\mathrm{N}}$ and $F_{\mathrm{vM}}$ - tend to reach equilibrium at a higher $\sigma_{1}^{\prime}$, which is very similar to macromechanical behaviour that is, $K=\sigma_{3}^{\prime} / \sigma_{1}^{\prime}$ evolution in the $K-\sigma_{1}^{\prime}$ space in Figure 4(b). In other words, the micromechanical measures seem to be able to reflect the macromechanical quantities.

\section{Results of triaxial tests and DEM simulations}

A series of undrained triaxial compression tests for 21 isotropic and $14 K_{0}$ consolidated specimens was conducted. The range of $e_{0}$ values was $0 \cdot 497-0 \cdot 655$ and $p_{0}^{\prime}$ varied from 50 to $500 \mathrm{kPa}$, where subscript ' 0 ' denotes the start of shearing. The details of these tests are presented in Table 1. Another series of DEM simulations under undrained triaxial condition for 54 isotropic and $15 K_{0}$ consolidated specimens was conducted (Table 2). The range of $e_{0}$ values was $0 \cdot 395-0 \cdot 729$ and $p_{0}^{\prime}$ varied from 19 to $1000 \mathrm{kPa}$. Some of these undrained simulations were part of another project and previously published by Nguyen et al. (2017).

\section{Undrained behaviour and characteristic feature}

The $\mathrm{F}$ behaviours in $q-p^{\prime}$ and $q-\varepsilon_{\mathrm{q}}$ spaces after isotropic and $K_{0}$ consolidations of loose triaxial specimen and DEM simulation under triaxial conditions are presented in Figures 6(a) and 6(b) and Figures 6(c) and 6(d), respectively. The ESPs of two isotropic triaxial specimens (YS-CIU04 and YS-CIU05) started from $q=0$ and raised to a peak $q\left(q_{\text {peak }}\right)$. The strain softening or static liquefaction - that is, $\mathrm{d} q / \mathrm{d} \varepsilon_{\mathrm{q}}<0$ - was triggered just after $q_{\text {peak }}$. The $\eta_{\text {IS }}$ of YS-CIU04 and YS-CIU05 were 0.742 and 0.762 , respectively, as shown by dotted lines in Figure 6(a). However, after $K_{0}$ consolidation, $\mathrm{YS}-\mathrm{K}_{0} \mathrm{U} 10$ and $\mathrm{YS}-\mathrm{K}_{0} \mathrm{U} 11$ reached the initial $q$ of 135 and $193 \mathrm{kPa}$, respectively. During undrained shearing, the $q$ of these two triaxial tests quickly rose to a $q_{\text {peak }}$, and then strain softened to static liquefaction. The $\eta_{\text {IS }}$ of YS$\mathrm{K}_{0} \mathrm{U} 10$ and $\mathrm{YS}-\mathrm{K}_{0} \mathrm{U} 11$ were $0 \cdot 726$ and $0 \cdot 796$, respectively. There was no obvious correlation between $\eta_{\text {Is }}$ and consolidation type for these tests. This may be due to the fact that these tests had very different initial $q, e$ and $p^{\prime}$. The effect of these variables is discussed later. The stress-strain behaviour of these triaxial tests are shown in the $q-\varepsilon_{\mathrm{q}}$ space in Figure $6(\mathrm{~b})$. Interestingly, $q_{\text {peak }}$ occurred quickly for $K_{0}$-consolidated specimens (approximately
$0.5 \%$ strain), whereas the $q_{\text {peak }}$ of isotropic consolidated specimen occurs at around $2-5 \%$ strain, as shown in Figure $6(\mathrm{~b})$.

Similar to triaxial tests, the DEM simulation of loose assembly under triaxial condition showed $q_{\text {peak }}$ for both isotropic and $K_{0}$

Table 1. The detail of triaxial tests

\begin{tabular}{|c|c|c|c|c|c|c|}
\hline Test number & $e_{0}$ & $p_{0}^{\prime}: \mathrm{kPa}$ & $p_{\mathrm{CS}}^{\prime}: \mathrm{kPa}$ & OB & $\psi_{0}$ & $D_{r}$ \\
\hline YS-CIU01 & 0.643 & 100 & 3 & $\mathrm{~F}$ & 0.053 & 0.531 \\
\hline YS-CIU02 & 0.655 & 200 & 6 & $\mathrm{~F}$ & 0.085 & 0.504 \\
\hline YS-CIU03 & 0.645 & 350 & 5 & $\mathrm{~F}$ & 0.099 & 0.527 \\
\hline YS-CIU04 & 0.642 & 100 & 5 & $\mathrm{~F}$ & 0.052 & 0.533 \\
\hline YS-CIU05 & 0.629 & 200 & 10 & $\mathrm{~F}$ & 0.059 & 0.561 \\
\hline YS-CIU06 & 0.610 & 300 & 5 & $\mathrm{~F}$ & 0.056 & 0.601 \\
\hline YS-CIU07 & 0.625 & 350 & 17 & $\mathrm{~F}$ & 0.079 & 0.569 \\
\hline YS-CIU08 & 0.628 & 50 & 3 & $\mathrm{~F}$ & 0.025 & 0.563 \\
\hline YS-CIU09 & 0.614 & 100 & 3 & $\mathrm{~F}$ & 0.024 & 0.592 \\
\hline YS-CIU10 & 0.607 & 200 & 13 & $\mathrm{~F}$ & 0.037 & 0.608 \\
\hline YS-CIU11 & 0.608 & 350 & 12 & $\mathrm{~F}$ & 0.062 & 0.605 \\
\hline YS-CIU12 & 0.600 & 100 & 19 & $\mathrm{~F}$ & 0.010 & 0.622 \\
\hline YS-CIU13 & 0.599 & 200 & 30 & $\mathrm{~F}$ & 0.029 & 0.625 \\
\hline YS-CIU14 & 0.595 & 200 & 30 & $\mathrm{~F}$ & 0.025 & 0.633 \\
\hline YS-CIU15 & 0.564 & 350 & 292 & $\mathrm{~F}$ & 0.018 & 0.699 \\
\hline YS-CIU16 & 0.539 & 200 & 283 & NF & -0.031 & 0.753 \\
\hline YS-CIU17 & 0.527 & 350 & 589 & $\mathrm{NF}$ & -0.019 & 0.778 \\
\hline YS-CIU18 & 0.493 & 100 & 575 & NF & -0.097 & 0.851 \\
\hline YS-CIU19 & 0.480 & 350 & 771 & $\mathrm{NF}$ & -0.066 & 0.879 \\
\hline YS-CIU2O & 0.621 & 100 & 3 & $\mathrm{~F}$ & 0.031 & 0.578 \\
\hline YS-CIU21 & 0.602 & 200 & 21 & $\mathrm{~F}$ & 0.032 & 0.618 \\
\hline YS-Ko U01 & 0.531 & 170 & 97 & LF & -0.008 & 0.769 \\
\hline YS-Ko U02 & 0.514 & 260 & 202 & LF & -0.013 & 0.806 \\
\hline YS-Ko U03 & 0.516 & 364 & 148 & LF & 0.005 & 0.802 \\
\hline YS-K $\mathrm{K}_{0} \mathrm{U} 04$ & 0.515 & 492 & 368 & LF & 0.018 & 0.804 \\
\hline YS-Ko U05 & 0.562 & 108 & 8 & $\mathrm{~F}$ & 0.017 & 0.704 \\
\hline YS-Ko U06 & 0.556 & 201 & 3 & $\mathrm{~F}$ & 0.025 & 0.716 \\
\hline YS-K $\mathrm{K}_{0} \cup 07$ & 0.555 & 278 & 31 & $\mathrm{~F}$ & 0.034 & 0.719 \\
\hline YS-K $K_{0} \cup 08$ & 0.553 & 468 & 121 & LF & 0.054 & 0.723 \\
\hline YS-Ko U09 & 0.584 & 137 & 3 & $\mathrm{~F}$ & 0.044 & 0.657 \\
\hline$Y S-K_{0} U 10$ & 0.573 & 211 & 6 & $F$ & 0.043 & 0.680 \\
\hline YS-Ko U11 & 0.573 & 272 & 10 & $\mathrm{~F}$ & 0.051 & 0.680 \\
\hline YS-Ko U12 & 0.559 & 371 & 19 & $\mathrm{~F}$ & 0.049 & 0.710 \\
\hline YS-Ko U13 & 0.614 & 193 & 3 & $\mathrm{~F}$ & 0.082 & 0.594 \\
\hline YS-Ko U14 & 0.479 & 243 & 624 & NF & -0.046 & 0.881 \\
\hline
\end{tabular}

$\mathrm{OB}$, observed behaviour; NF, non-flow; LF, limited flow; F, flow 
Table 2. The details of DEM simulations (continued in next column)

\begin{tabular}{|c|c|c|c|c|c|c|c|}
\hline $\begin{array}{l}\text { Simulation } \\
\text { number }\end{array}$ & $e_{0}$ & $\begin{array}{l}p_{0}^{\prime}: \\
\mathrm{kPa}\end{array}$ & $\begin{array}{l}p_{\mathrm{CS}}^{\prime}: \\
\mathrm{kPa}\end{array}$ & OB & $\psi_{0}$ & $D_{10}$ & $C_{\mathrm{NO}}$ \\
\hline DE-C & 0.538 & 50 & 1500 & NF & $-0 \cdot 130$ & 0.606 & $7 \cdot 738$ \\
\hline DE-CIU02 & 0.412 & 50 & 3268 & NF & -0.256 & 0.999 & 8.443 \\
\hline DE-CIU04 & 0.582 & 50 & 809 & NF & -0.086 & 0.467 & \\
\hline DE-CIU05 & 0.631 & 50 & 393 & NF & -0.037 & 0.312 & 6.929 \\
\hline DE-CIU07 & 0.660 & 100 & 3 & $\mathrm{~F}$ & 0.000 & 0.193 & $5 \cdot 283$ \\
\hline DE-CIU09 & 0.625 & 300 & 321 & NF & -0.011 & 0.223 & $5 \cdot 760$ \\
\hline DE-CIU10 & 0.609 & 600 & 577 & LF & 0.003 & 0.174 & $6 \cdot 230$ \\
\hline DE-CIU11 & 0.633 & 216 & 335 & NF & -0.012 & 0.228 & $5 \cdot 401$ \\
\hline DE-CIU12 & 0.676 & 50 & 2 & E & 0.008 & 0.172 & $4 \cdot 457$ \\
\hline DE-CIU13 & 0.678 & 50 & 1 & $\mathrm{~F}$ & 0.010 & 0.165 & 4.305 \\
\hline DE-CIU14 & 0.670 & 100 & 1 & $\mathrm{~F}$ & 0.010 & 0.161 & 4.534 \\
\hline DE-CIU15 & 0.729 & 19 & 0.231 & $\mathrm{~F}$ & 0.055 & 0.033 & 4.437 \\
\hline DE-C & 0.704 & 28 & 1 & $\mathrm{~F}$ & 0.032 & $0 \cdot 100$ & 4.407 \\
\hline & .687 & 36 & 1 & $\mathrm{~F}$ & 0.016 & 0.148 & $4 \cdot 370$ \\
\hline & 642 & 150 & 169 & NF & -0.012 & 0.228 & $5 \cdot 136$ \\
\hline & 635 & 200 & 284 & NF & -0.012 & 0.228 & $5 \cdot 373$ \\
\hline & 0.492 & 900 & 1981 & NF & -0.088 & & \\
\hline & 0.573 & 900 & 936 & LF & -0 & & 7.659 \\
\hline & 0 & 100 & 3 & $\mathrm{~F}$ & -0.001 & & 4.746 \\
\hline & 0 & 200 & 18 & LF & & & 46 \\
\hline & 0 & 75 & 2 & $\mathrm{~F}$ & & & 45 \\
\hline & 0.577 & 1000 & 921 & LF & 05 & 72 & $6 \cdot 596$ \\
\hline 1 & 0.631 & 357 & 269 & LF & 0.002 & 0.179 & $5 \cdot 831$ \\
\hline J33 & 0.579 & 100 & 887 & NF & -0.081 & 0.454 & $7 \cdot 518$ \\
\hline DE-CIU34 & 0.628 & 100 & 401 & NF & -0.032 & 0.297 & $7 \cdot 164$ \\
\hline DE-CIU35 & 0.648 & 100 & 251 & NF & -0.012 & 0.232 & $6 \cdot 567$ \\
\hline DE-CIU36 & 0.639 & 200 & 235 & NF & -0.007 & 0.213 & 6.900 \\
\hline J37 & 0.632 & 285 & 371 & NF & -0.005 & 0.202 & 6.956 \\
\hline$D E$ & 0.629 & 335 & 348 & NF & -0.003 & 0.197 & 6.964 \\
\hline & 631 & 240 & 315 & NF & -0.011 & 0.225 & $5 \cdot 617$ \\
\hline & .632 & 230 & 282 & NF & -0.011 & 0.226 & 5.579 \\
\hline & 496 & 0 & 1964 & NF & -0 & 0.736 & 7.966 \\
\hline & & 0 & 2521 & NF & -0 & & \\
\hline & 0.615 & 600 & 498 & LF & 09 & & 5.870 \\
\hline & 4 & 480 & 1550 & NF & $-0 \cdot 103$ & 50 & 7.960 \\
\hline & 9 & 498 & 91 & NF & -0.016 & 44 & $7 \cdot 494$ \\
\hline & 5 & 300 & 38 & NF & -0.011 & 23 & 5.743 \\
\hline & 5 & 300 & 50 & NF & 11 & 23 & 43 \\
\hline & 7 & 100 & 1959 & NF & -0 & 0.718 & $7 \cdot 307$ \\
\hline U66 & 0.470 & 600 & 2389 & NF & $-0 \cdot 136$ & 0.696 & $7 \cdot 661$ \\
\hline DE-CIU67 & 0.450 & 1000 & 2616 & NF & $-0 \cdot 123$ & 0.698 & $7 \cdot 843$ \\
\hline DE-CIU51 & 0.611 & 600 & 590 & NF & 0.005 & 0.166 & $5 \cdot 327$ \\
\hline DE-CIU52 & 0.660 & 107 & 4 & $\mathrm{~F}$ & 0.001 & 0.190 & 4.517 \\
\hline DE-CIU53 & 0.667 & 100 & 3 & $\mathrm{~F}$ & 0.007 & $0 \cdot 171$ & $4 \cdot 289$ \\
\hline DE-C & 0.673 & 100 & 2 & $\mathrm{~F}$ & 0.013 & 0.151 & 4.325 \\
\hline DE- & 0.679 & 100 & $0 \cdot 224$ & $\mathrm{~F}$ & 0.019 & 0.132 & $4 \cdot 184$ \\
\hline U56 & 0.661 & 50 & 4 & $\mathrm{~F}$ & 0.000 & 0.220 & $4 \cdot 161$ \\
\hline DE-CIU57 & 0.613 & 600 & 581 & LF & 0.007 & 0.158 & $5 \cdot 541$ \\
\hline U58 & 0.558 & 600 & 1213 & NF & -0.048 & 0.366 & $6 \cdot 046$ \\
\hline DE-CIU59 & 0.580 & 600 & 1014 & NF & -0.026 & 0.285 & $5 \cdot 604$ \\
\hline DE-CIU60 & 0.620 & 600 & 498 & LF & 0.014 & 0.133 & $5 \cdot 509$ \\
\hline DE-CIU68 & 0.497 & 100 & 1939 & NF & $-0 \cdot 163$ & 0.718 & $7 \cdot 135$ \\
\hline & 0.470 & 600 & 2382 & NF & $-0 \cdot 136$ & 0.696 & $7 \cdot 471$ \\
\hline DE-CIU70 & 0.450 & 1000 & 2660 & NF & -0.123 & 0.698 & $7 \cdot 657$ \\
\hline DE-Ko U02 & 0.395 & 459 & 3800 & NF & -0.224 & 0.996 & 8.087 \\
\hline DE-Ko U03 & 0.511 & 481 & 1548 & NF & $-0 \cdot 106$ & 0.571 & $7 \cdot 121$ \\
\hline$D E-K_{0} \cup 04$ & 0.592 & 502 & 736 & NF & -0.023 & 0.269 & $6 \cdot 379$ \\
\hline$D E-K_{0} \cup 05$ & 0.684 & 68 & 1 & $\mathrm{~F}$ & 0.019 & 0.135 & $4 \cdot 120$ \\
\hline DE-K $K_{0} \cup 06$ & 0.694 & 36 & $0 \cdot 384$ & $\mathrm{~F}$ & 0.023 & $0 \cdot 127$ & $4 \cdot 106$ \\
\hline & 061 & 94 & 2 & $\mathrm{~F}$ & 0.000 & 0.194 & $4 \cdot 744$ \\
\hline$D E-K_{0} U 11$ & 0.668 & 68 & 1 & $\mathrm{~F}$ & 0.004 & $0 \cdot 184$ & $4 \cdot 336$ \\
\hline
\end{tabular}

Table 2. Continued

\begin{tabular}{|c|c|c|c|c|c|c|c|}
\hline $\begin{array}{l}\text { Simulation } \\
\text { number }\end{array}$ & $e_{0}$ & $\begin{array}{l}p_{0}^{\prime}: \\
\mathrm{kPa}\end{array}$ & $\begin{array}{l}p_{\mathrm{CS}}^{\prime}: \\
\mathrm{kPa}\end{array}$ & OB & $\psi_{0}$ & $D_{10}$ & $C_{\mathrm{NO}}$ \\
\hline DE-Ko U14 & 0.673 & 52 & 1 & $\mathrm{~F}$ & 0.006 & 0.179 & $4 \cdot 173$ \\
\hline DE-Ko U15 & 0.616 & 562 & 579 & LF & 0.006 & $0 \cdot 162$ & $5 \cdot 199$ \\
\hline $\mathrm{DE}-\mathrm{K}_{0} \mathrm{U} 17$ & 0.607 & 514 & 582 & LF & -0.007 & 0.212 & $6 \cdot 132$ \\
\hline DE-Ko $U 18$ & 0.551 & 492 & 1327 & NF & -0.065 & 0.423 & $6 \cdot 888$ \\
\hline DE-Ko U19 & 0.614 & 525 & 505 & LF & 0.001 & 0.182 & 5.699 \\
\hline$D E-K_{0} U 20$ & 0.552 & 481 & 1246 & NF & -0.066 & 0.424 & $6 \cdot 891$ \\
\hline$D E-K_{0} \cup 23$ & 0.698 & 29 & 0.472 & $\mathrm{~F}$ & 0.040 & 0.120 & $4 \cdot 153$ \\
\hline DE-K $\mathrm{K}_{0} \mathrm{U} 24$ & 0.709 & 22 & 0.303 & $\mathrm{~F}$ & 0.051 & 0.092 & $4 \cdot 283$ \\
\hline
\end{tabular}

consolidations as presented in Figure 6(c). However, $\eta_{\text {IS }}$ of $\mathrm{DE}-\mathrm{K}_{0} \mathrm{U} 05$ and $\mathrm{DE}-\mathrm{K}_{0} \mathrm{U} 11$ were 0.805 and 0.849 , respectively, which were higher than $\eta_{\text {IS }}$ of 0.240 and 0.418 for DE-CIU13 and DE-CIU14, respectively. Note that $\eta_{\mathrm{IS}}$ values for $K_{0}$ consolidated were significantly higher that isotropic consolidation. $\eta$, after $K_{0}$ consolidated corresponding to initial $q$ at the start of undrained shearing, was somewhat close to the CS stress ratio $M$. The stress-strain behaviour of these DEM simulations showed a quick drop from $q_{\text {peak }}$ to $q=0$ at CS as shown in Figure 6(d).

The NF behaviour in $q-p^{\prime}$ and $q-\varepsilon_{\mathrm{q}}$ spaces after isotropic and $K_{0}$ consolidations of dense triaxial specimen and DEM simulation under triaxial conditions are presented in Figures 7(a) and 7(b) and Figures 7(c) and 7(d), respectively. Usually, LF and NF responses exhibit the PT state at the knee of the ESP, which can be defined as the state of $\mathrm{d} p^{\prime}=0$ on the ESP in the $q-p^{\prime}$ space (Lade and Ibsen, 1997). However, other researchers argued that the PT state separates the contractive to dilative tendency at $\mathrm{d} \varepsilon_{\mathrm{v}}=0$; therefore, the equivalence of this for the undrained test would be $\mathrm{d} \Delta u=0$. Hence, Sukumaran et al. (1996) define PT state as a state of $\mathrm{d} \Delta u=0$. Although the triaxial test and DEM simulations in Figure 7 did not show the clear knee of ESP, the latter definition allowed the identification of PT states at $\mathrm{d} \Delta u=0$. The stress ratio at PT $\left(\eta_{\mathrm{PT}}\right)$ on the ESP is considered as an important characteristic feature and has been used in constitutive formulation (Manzari and Dafalias, 1997; Wood et al., 1994). $\eta_{\mathrm{PT}}$ in triaxial tests occurred below the $M$-line, and after that, ESPs follow the $M$-line as shown in Figure 7(a). It appears that both $K_{0}$ and isotropic consolidation tests tend to a unique CSL in the $q-p^{\prime}$ space - that is, the $M$-line. Figure 7(c) shows that ESPs of DEM simulations evolved beyond the CSL ( $M$-line) and then come back to CS at large strain $\left(\varepsilon_{\mathrm{q}}>\right.$ $15 \%) . \eta_{\mathrm{PT}}$ was also higher than $M$. The stress-strain paths for both triaxial and DEM simulations showed very similar patterns of strain hardening as shown in Figures 7(b) and 7(d). Note that the $\Delta u$ development in Figures 6 and 7 exhibits a similar pattern to what was observed in Figure 1(c), and $\Delta u$ data for these tests are shown in Figures 1 and 2 in the online supplementary material.

\section{Relationship between density index and characteristic} features

To evaluate the effect of density index, the relative density $\left(D_{\mathrm{r}}\right)$ as defined in the following equation, was primarily used for triaxial specimen of YS sand. 
Geotechnical Research

Volume 5 Issue GR4
The effect of consolidation on undrained

behaviour of granular materials:

experiment and DEM simulation

Rahman, Nguyen and Rabbi

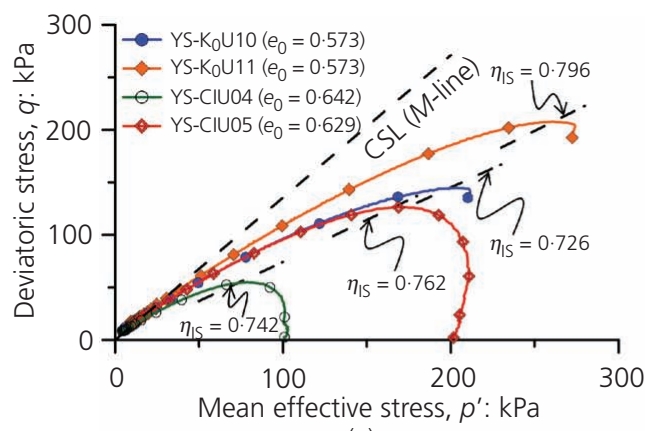

(a)

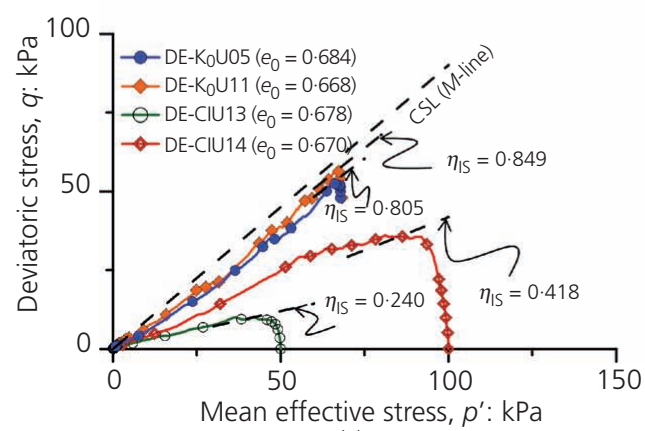

(c)

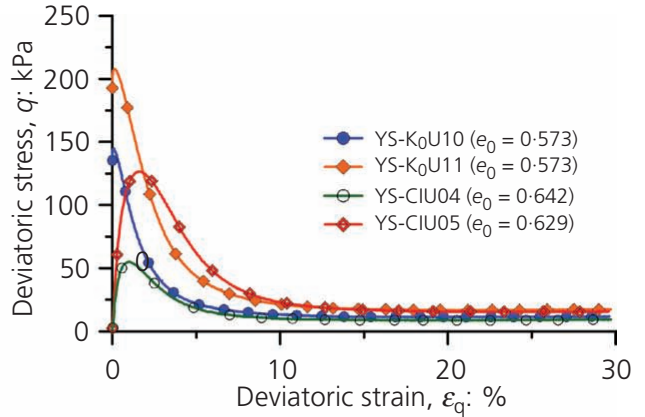

(b)

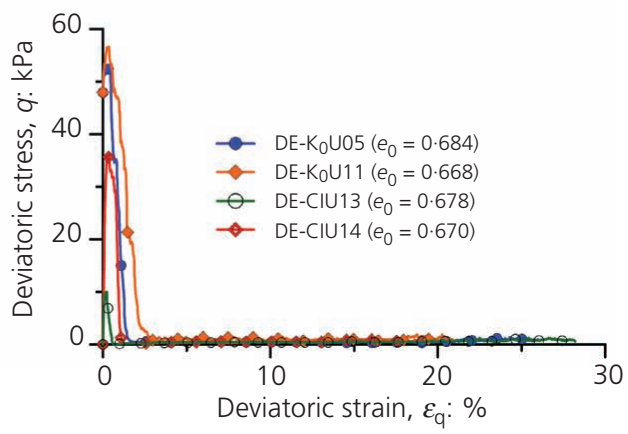

(d)

Figure 6. Undrained behaviours (F) of loose YS sand and DEM ellipsoids after isotropic and $K_{0}$ consolidations: (a) in $q-p^{\prime}$ space (triaxial tests); (b) in $q-\varepsilon_{\mathrm{q}}$ space (triaxial tests); (c) in $q-p^{\prime}$ space (DEM); and (d) in $q-\varepsilon_{\mathrm{q}}$ space (DEM)

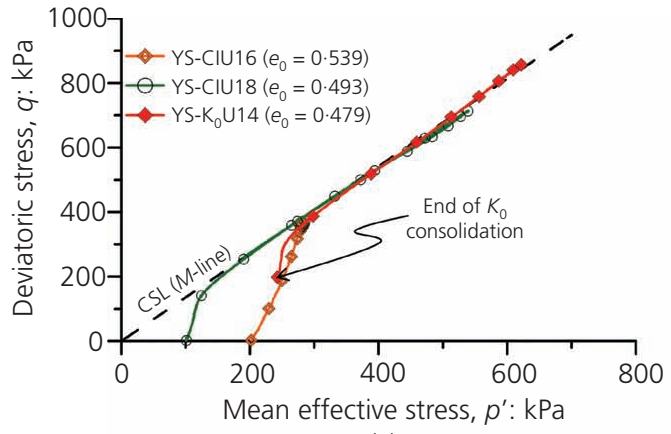

(a)

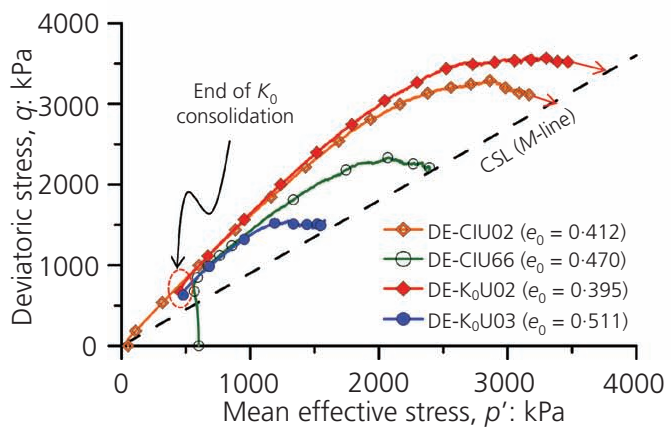

(c)

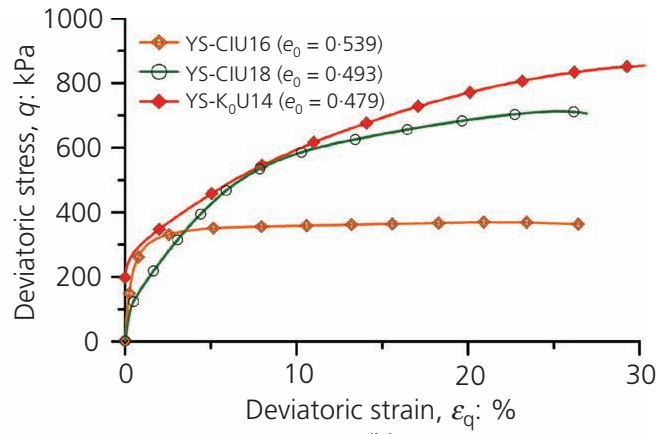

(b)

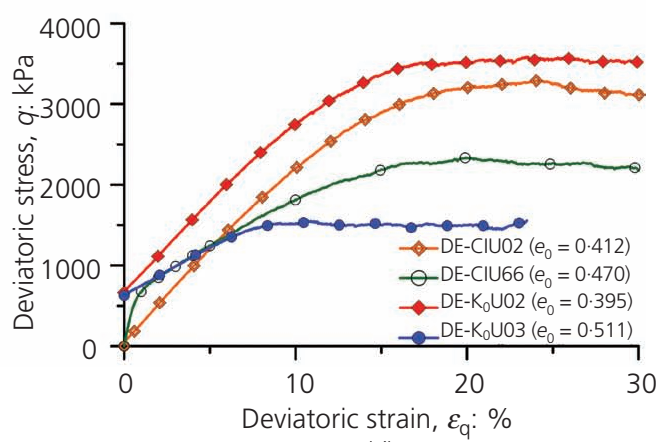

(d)

Figure 7. Undrained behaviour (NF) of dense YS sand and DEM ellipsoids after isotropic and $K_{0}$ consolidations: (a) in the $q-p^{\prime}$ space (triaxial tests); (b) in the $q-\varepsilon_{\mathrm{q}}$ space (triaxial tests); (c) in the $q-p^{\prime}$ space (DEM); and (d) in the $q-\varepsilon_{\mathrm{q}}$ space (DEM) 
The effect of consolidation on undrained behaviour of granular materials: experiment and DEM simulation Rahman, Nguyen and Rabbi

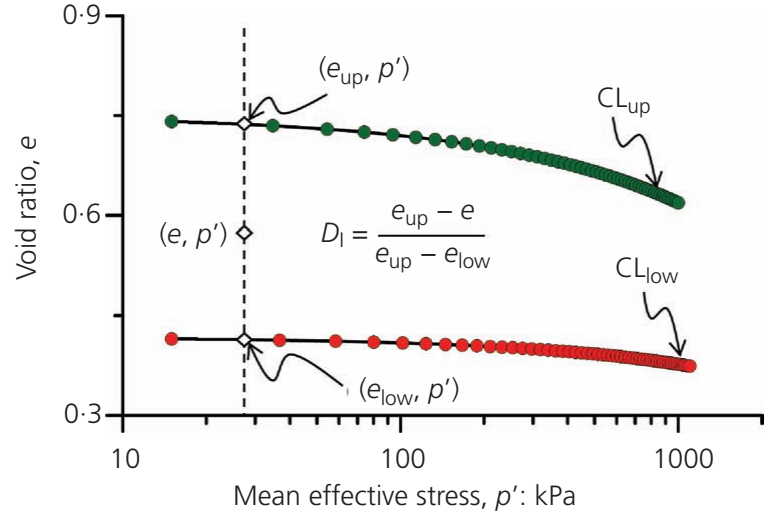

Figure 8. Defining densification index $\left(D_{1}\right)$ after Zhang et al. (2018)

10. $D_{\mathrm{r}}=\frac{e_{\max }-e}{e_{\max }-e_{\min }}$

where $e_{\max }$ and $e_{\min }$ are the maximum and minimum void ratios, respectively. However, the measurements of $e_{\max }$ and $e_{\min }$ are challenging and problematic in DEM; therefore, an alternative measure of $D_{\mathrm{r}}$, called densification index $\left(D_{\mathrm{I}}\right)$, was adopted to capture the density of the assembly of ellipsoids. $D_{\text {I }}$ was defined as the state of soil relative to the upper and lower boundary consolidation lines (see Figure 8 ) as proposed by Zhang et al. (2018). $D_{\text {I }}$ can be expressed as follows.
11. $D_{\mathrm{I}}=\frac{e_{\mathrm{up}}-e}{e_{\mathrm{up}}-e_{\mathrm{low}}}$

where $e_{\text {up }}$ and $e_{\text {low }}$ are the corresponding void ratios on upper and lower consolidation lines, respectively. The upper consolidation line $\left(\mathrm{CL}_{\mathrm{up}}\right)$ was the consolidation line of loosest assembly, whereas the consolidation line of densest assembly was the lower consolidation line $\left(\mathrm{CL}_{\mathrm{low}}\right)$. So, the density indices for the triaxial tests and DEM simulation were $D_{\mathrm{r}}$ and $D_{\mathrm{I}}$, respectively, in this study. Note that $D_{\mathrm{r}}$ and $D_{\mathrm{I}}$ are slightly different as $D_{\mathrm{I}}$ is dependent on $p_{0}^{\prime}$, and therefore, its value for the same $e$ can change with consolidation pressure $p^{\prime}$. However, if the isotropic consolidation lines (ICLs) are parallel, the value of $D_{\mathrm{I}}$ does not change with $p^{\prime}$.

\section{Relationship between density index and $\eta_{1 \mathrm{~S}}$ state}

The relationships between $\eta_{\mathrm{IS}}$ and the density indices - that is, $D_{\mathrm{r}}$ and $D_{\mathrm{I}}$ - are shown in Figure 9 for both triaxial and DEM simulations. In general, $\eta_{\mathrm{IS}}$ was increased with $D_{\mathrm{r}}$ for both $K_{0^{-}}$ and isotropically consolidated specimen in triaxial tests as shown in Figure 9(a). The root mean square deviation (RMSD) of the best-fit trend was $0 \cdot 100$. The $D_{\mathrm{r}}$ values of $K_{0}$ tests were comparatively higher than that of isotropic tests, as $e$ after $K_{0}$ consolidation were mostly lower than $e$ after isotropic consolidation (as shown in Figure 4(a)). Similarly, $\eta_{\text {IS }}$ was increased with $D_{\mathrm{I} 0}$ in the $\eta_{\mathrm{IS}}-D_{\mathrm{I} 0}$ space for both $K_{0}$ and isotropically consolidated specimen in DEM simulation as shown in Figure 9(b), where $D_{\mathrm{IO}}$ is the densification index at the start of

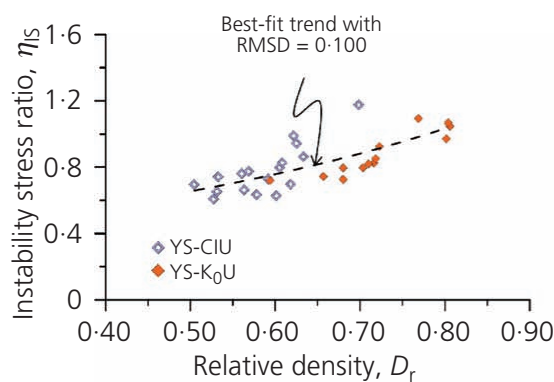

(a)

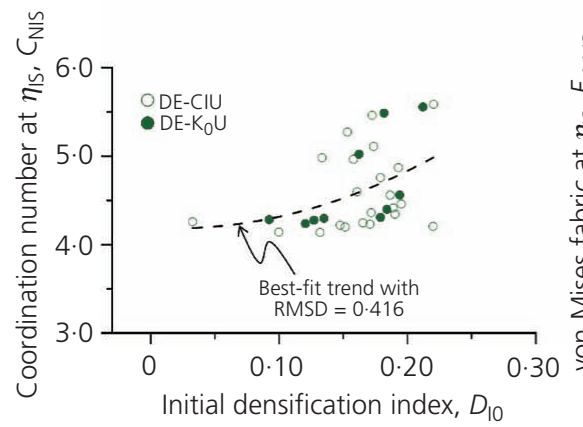

(c)

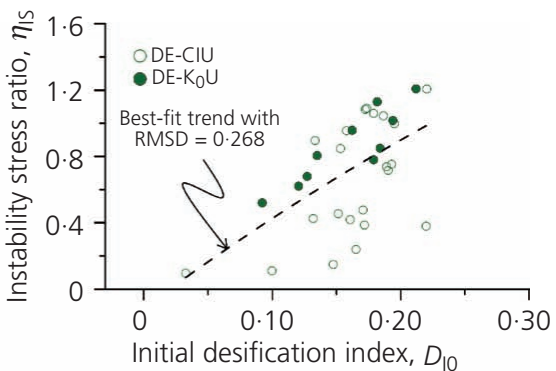

(b)

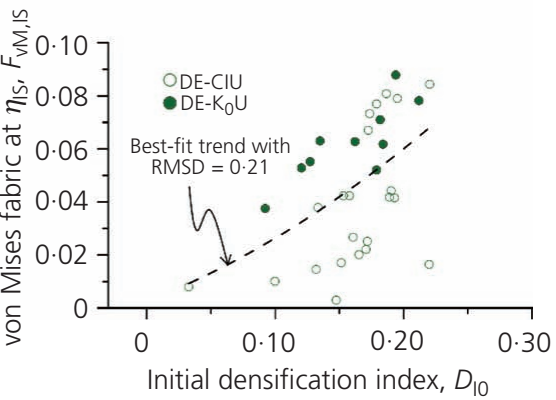

(d)

Figure 9. Relationship between instability state and density state: (a) in the $\eta_{1 \mathrm{~S}}-D_{\mathrm{r}}$ space (triaxial test); (b) in the $\eta_{1 \mathrm{~S}}-D_{10}$ space (DEM); (c) in the $C_{\mathrm{NIS}}-D_{10}$ space (DEM); and (d) in the $F_{\mathrm{vM}}-D_{10}$ space (DEM) 
shearing. The RMSD of the best-fit trend was $0 \cdot 268$. The $\eta_{\text {IS }}$ of $K_{0}$ simulations seem to be higher than that of isotropic simulation. The $C_{\mathrm{N}}$ at instability $\left(C_{\mathrm{NIS}}\right)$ increased with $D_{\mathrm{I} 0}$, but it did not exhibit any dependency on the consolidation type (the RMSD of this relation was 0.416 ) as shown in Figure 9(c). The $F_{\mathrm{vM}}$ at instability $\left(F_{\mathrm{vM}, \mathrm{IS}}\right)$ also increased with $D_{\mathrm{I} 0}$, and $F_{\mathrm{vM}, \mathrm{IS}}$ of $K_{0}$ simulation seems to be higher than that of the isotropic simulation (the RMSD of this relation was 0.021) as shown in Figure 9(d). The pattern of the $F_{\mathrm{vM}, \mathrm{IS}}-D_{\mathrm{I} 0}$ relation in Figure $9(\mathrm{~d})$ is somewhat similar to the $\eta_{\mathrm{IS}}-D_{\mathrm{I} 0}$ relation in Figure 9(b).

\section{Relationship between density index and PT state}

Figure 10(a) shows that the $\eta_{\mathrm{PT}}$ decreases with $D_{\mathrm{r}}$ in the $\eta_{\mathrm{PT}}-D_{\mathrm{r}}$ space for triaxial tests. The best-fit trend for $\eta_{\mathrm{PT}}$ and $D_{\mathrm{r}}$ was higher for $K_{0}$ consolidation than that of for isotropic consolidation. These two trends appear to meet at $D_{\mathrm{r}}=0 \cdot 90$. However, the $\eta_{\mathrm{PT}}$ increased gradually with $D_{\mathrm{I} 0}$ in the $\eta_{\mathrm{PT}}-D_{\mathrm{I} 0}$ space for DEM simulation as shown in Figure 10(b). Interestingly, the best-fit trend did not have any obvious dependency on consolidation type for the DEM simulations of this study, which is different from what was observed for triaxial data in Figure 10(a).

Relationship between density index and flow potential $\left(u_{\mathrm{F}}\right)$ The flow potential $\left(u_{\mathrm{F}}\right)$, as defined in Equation 12, is often used to characterise granular material behaviour.

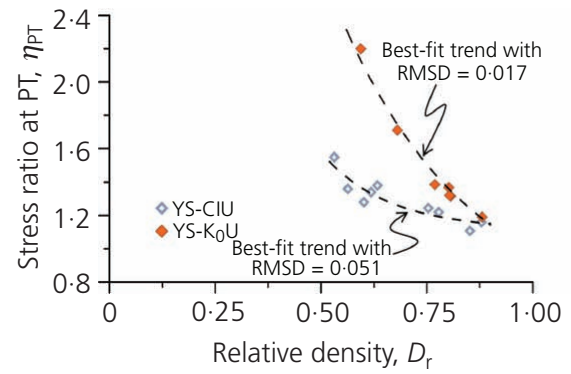

(a)
12. $u_{\mathrm{F}}=1-p_{\mathrm{PT}}^{\prime} / p_{0}^{\prime}$

where $p_{\mathrm{PT}}^{\prime}$ is the mean effective confining stress at the PT state. Figure 11(a) shows that the $u_{\mathrm{F}}$ decreases with $D_{\mathrm{r}}$ in the $u_{\mathrm{F}}-D_{\mathrm{r}}$ space for triaxial tests. The best-fit line has an RMSD of $0 \cdot 361$. Note that the $u_{\mathrm{F}}$ values can be negative for $p_{\mathrm{PT}}^{\prime}$ higher than $p_{0}^{\prime}$ in Equation 12 - that is, the PT occurs at a higher stress level $\left(p^{\prime}\right)$ than the initial state of $p_{0}^{\prime}$. Unlike the $\eta_{\mathrm{PT}}-D_{\mathrm{I} 0}$ relation in Figure $10(\mathrm{~b}), u_{\mathrm{F}}$ was decreased with $D_{\mathrm{I} 0}$ in the $u_{\mathrm{F}}-D_{\mathrm{I} 0}$ space, and two distinct relations were observed for isotropic and $K_{0}$ consolidations for DEM simulation (see Figure 11(b)). Noticeably, most $u_{\mathrm{F}}$ values of $K_{0}$ simulations are relatively small, and some tend to negative.

The above investigation suggests that the overall qualitative behaviour of YS sand in triaxial testing can be captured by DEM simulation for triaxial testing with a simple linear contact model for ellipsoid particles. However, there are disagreements between the experiment and DEM data for some characteristic features, which require further investigation and development. Since $D_{\mathrm{r}}$ and $D_{\mathrm{I}}$ were not equivalent density indices, this study investigated the correlation of these characteristic features within the CSSM framework.

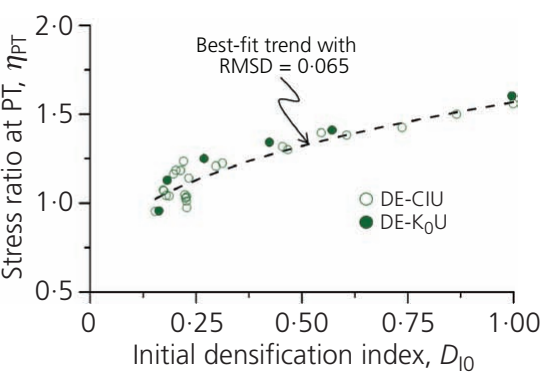

(b)

Figure 10. Correlations of $\eta_{\mathrm{PT}}$ : (a) with $D_{\mathrm{r}}$ in the $\eta_{\mathrm{PT}}-D_{\mathrm{r}}$ space and (b) with $D_{10}$ in the $\eta_{\mathrm{PT}}-D_{10}$ space

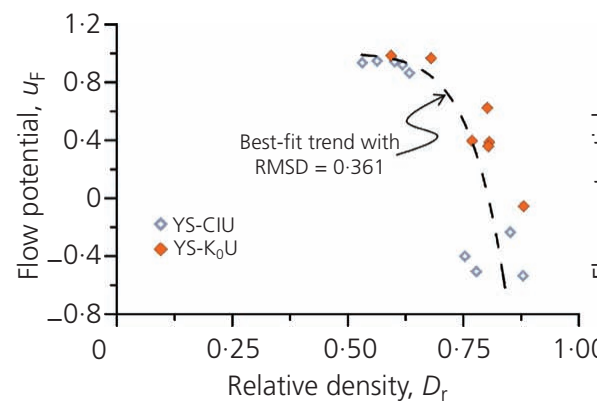

(a)

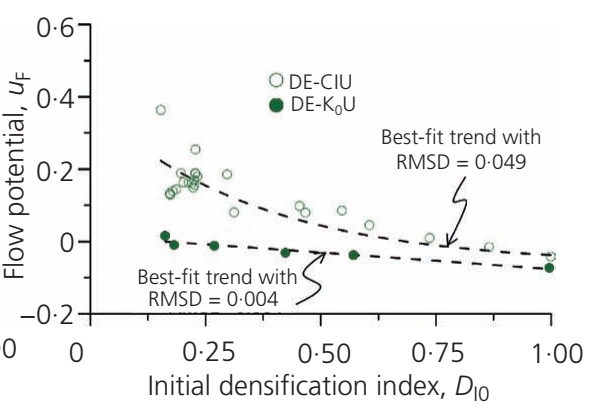

(b)

Figure 11. Correlations of $u_{\mathrm{F}}$ : (a) with $D_{\mathrm{r}}$ in the $u_{\mathrm{F}}-D_{\mathrm{r}}$ space (triaxial tests) and (b) with $D_{10}$ in the $u_{\mathrm{F}}-D_{10}$ space (DEM) 


\section{CSSM framework}

This study revisited the classical CSSM framework and investigated the CS behaviour of the YS sands and DEM ellipsoids.

\section{CS and CSL}

Figure 12(a) shows a pair of ESPs for DEM simulations with almost the same $e_{0}$ of $0.592-0.599$ and $p_{0}^{\prime}$ of $500 \mathrm{kPa}$ after $K_{0}$ and isotropic consolidations. As previously shown in Figure 7(c), the ESPs for DE-CIU71 and DE- $\mathrm{K}_{0} \mathrm{U} 04$ evolved beyond the CSL ( $M$-line) and then both the ESPs came back/approached towards the same CS $(\eta=M)$ at the end of simulation (see Figure 12(a)). Note that the stress state of DE- $\mathrm{K}_{0} \mathrm{U} 04$ after $K_{0}$ consolidation or at the start of undrained shearing was higher than $M$ as indicated by an arrow in Figure 12(a). The $F_{\mathrm{vM}}$ paths for these simulations evolved to a narrow zone (see Figure 12(b)). This zone was termed as 'CS zone', which was in line with the concept of CS fabric as discussed by Dafalias (2016). Interestingly, both the ESP and $F_{\mathrm{vM}}$ evolution paths were similar - that is, they go beyond the CS and come back to CS or a narrow zone - which suggests that $F_{\mathrm{vM}}$ may be a good micromechanical parameter for characterising the macromechanical behaviour.

Most triaxial tests and DEM simulations in this study reached clear CS. However, in few cases in which a clear CS was not reached, an extrapolation method, as discussed by Rahman and Lo (2014), was used. In this method, the rate of change of excess pore pressure $\left(\mathrm{d} \Delta u / \mathrm{d} \varepsilon_{\mathrm{q}}\right)$ is plotted against $\eta$ as shown in Figure 13 for both experimental and DEM data. The value of $\eta$ at CS $(M)$ can be estimated by extrapolating $\mathrm{d} \Delta u / \mathrm{d} \varepsilon_{\mathrm{q}}$ to 0 . Then, $p^{\prime}$ at the CS is estimated by extrapolating $\eta$ to $M$ in an $\eta-p^{\prime}$ plot. Such an extrapolation approach was also employed in other studies presented in the literature (Carrera et al., 2011; Murthy et al., 2007; Zhang et al., 2018). In the case of dense specimen in DEM simulation, $\mathrm{d} \Delta u / \mathrm{d} \varepsilon_{\mathrm{q}}=0$ was achieved twice: at the PT state and at the CS as shown in Figure 13(b). However, for the loose specimen in triaxial test, $\mathrm{d} \Delta u / \mathrm{d} \varepsilon_{\mathrm{q}}$ becomes 0 at the CS (Figure 13(a)) - that is, PT and CS may coincide.

The CS data points from triaxial experiments formed two different CSLs in the $e-\log \left(p^{\prime}\right)$ space for $K_{0}$ and isotropically consolidated specimens (Figure 14(a)). The finding of non-unique CSLs for YS sand for different consolidation conditions was somewhat unexpected and undesirable for the CS framework. This finding did not coincide with the authors' earlier findings of unique CSL under triaxial compression, irrespective of drainage conditions, for Sydney sand (Rahman et al., 2014a), pond ash (Zhang et al., 2018) and Hostun sand (Goudarzy et al., 2017). Therefore, it has also been verified for different drainage conditions and confirmed. The details of these verifications are published in a separate article (Rabbi et al., 2018). Note that the non-unique CSLs for different consolidations is not new. Finno and Rechenmacher (2003) observed non-unique CSLs for undrained loading after anisotropic consolidations. Fourie and Tshabalala (2005) observed slightly

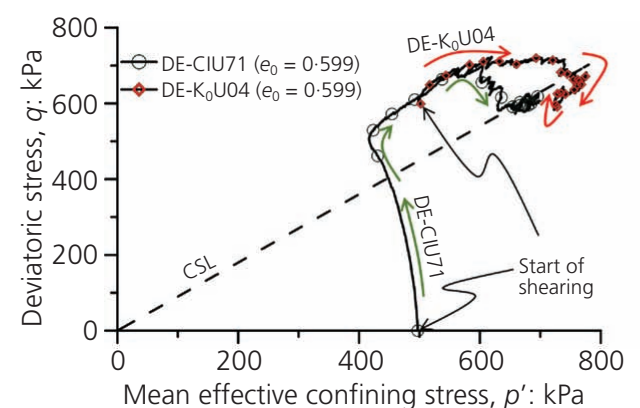

(a)

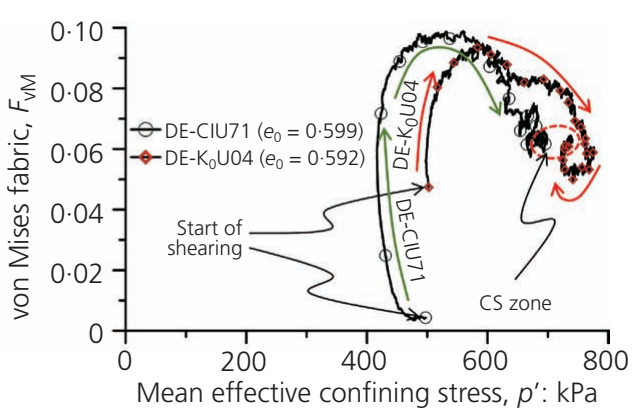

(b)

Figure 12. The evolution towards CS from DEM simulations in the (a) $q-p^{\prime}$ space and (b) $F_{\mathrm{vM}}-p^{\prime}$ space

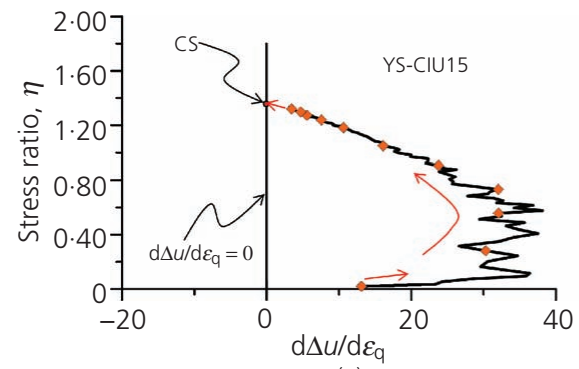

(a)

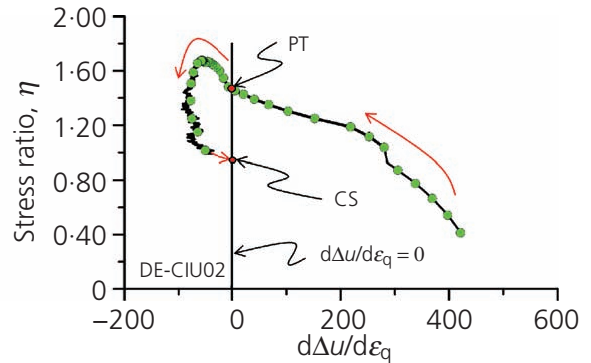

(b)

Figure 13. The extrapolation method for CS: (a) loose specimen (YS-CIU15, triaxial test) and (b) dense specimen (DE-CIU02, DEM) 


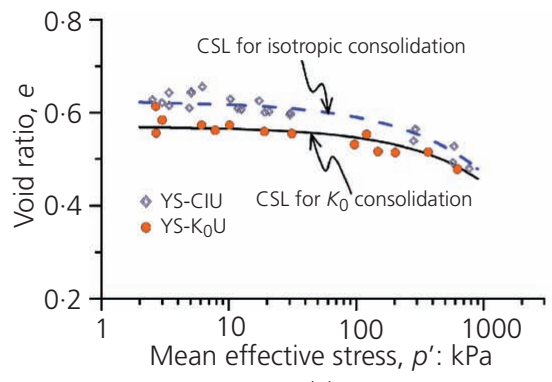

(a)

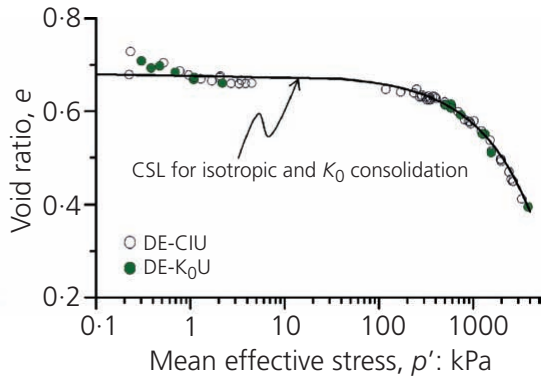

(b)

Figure 14. CSLs for isotropic and $K_{0}$ consolidation tests in the e-log $\left(p^{\prime}\right)$ space: (a) triaxial test and (b) DEM

different CSLs for undrained loading after isotropic and anisotropic consolidations (see Figure 15). However, the CS data points from DEM simulations of this study formed single CSL regardless of consolidation condition. Other DEM studies - for example, that of Zhou et al. (2017) - observed different critical state stress ratios $\left(q / p^{\prime}\right)$ for the drained condition after isotropic and anisotropic consolidations. However, they have not reported CSL in the $e-\log \left(p^{\prime}\right)$ space. This suggested that the assumption of

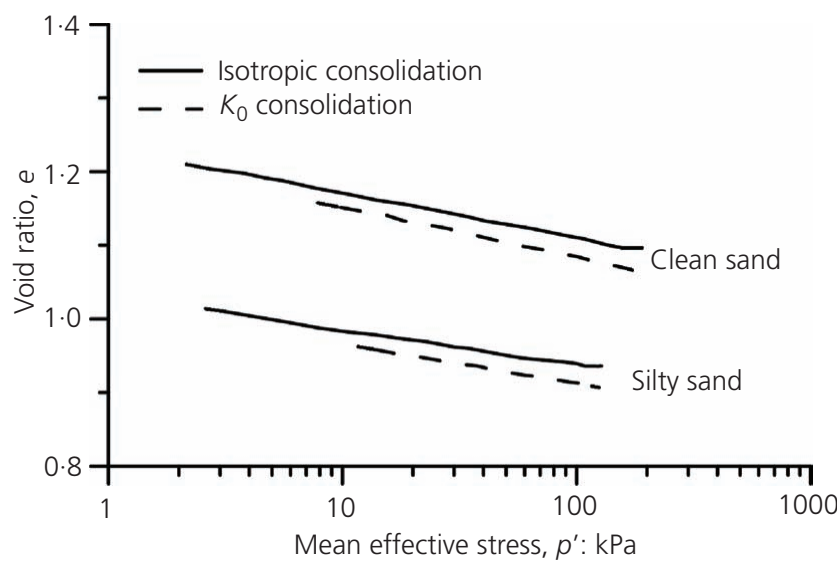

Figure 15. CSLs for triaxial tests after isotropic and $K_{0}$ consolidations, modified after Fourie and Tshabalala (2005)

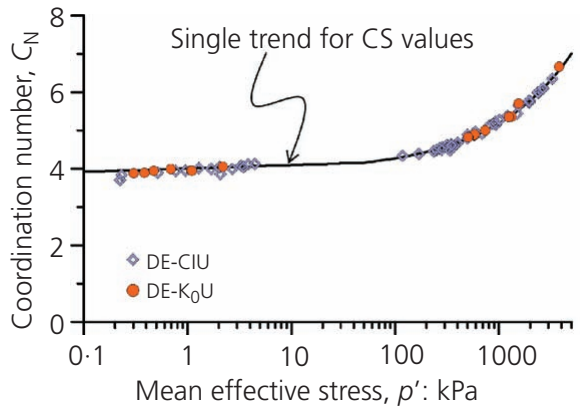

(a) a presumptive unique CSL from triaxial experiment or DEM simulation is not necessarily true for all granular materials. Further research is required to understand the material properties that might lead to such deviation from unique CSL.

Figure 16(a) shows that the $C_{\mathrm{N}}$ at $\mathrm{CS}$ forms unique relationships with $p^{\prime}$. Figure 16(b) shows that $F_{\mathrm{vM}}$ at $\mathrm{CS}$ in the $F_{\mathrm{vM}}-p^{\prime}$ space also forms a unique narrow CS zone for both $K_{0}$ and isotropic simulations. Although it was previously reported that the fabric evolved during undrained shearing (see Figure 12(b)), Figure 16(b) suggested that all $F_{\mathrm{vM}}$ values at $\mathrm{CS}$ formed a unique trend with the corresponding $p^{\prime}$. Hence, the fabric anisotropy, which represents the internal structure of the specimen, evolved from an initial value towards a CS value. This supported the fabric evolution and CS fabric concept of the anisotropic critical state theory (ACST) by $\mathrm{Li}$ and Dafalias (2012), and Dafalias (2016). The evolution of $F_{\mathrm{vM}}$ in this study was in fact a presentation of the fabric evolution in ACST. Although a fabric evolution model is already suggested for ACST, this study presents evidence for the evolution of fabric (see Figures 12(a) and 12(b)) and its relation with characteristic features to adopt necessary corrections on such model.

\section{Relation between state parameter $(\psi)$ and characteristic} features

The CSL in the $e-\log \left(p^{\prime}\right)$ space has been used as the reference state for soil behaviour. For example, a soil state above the CSL

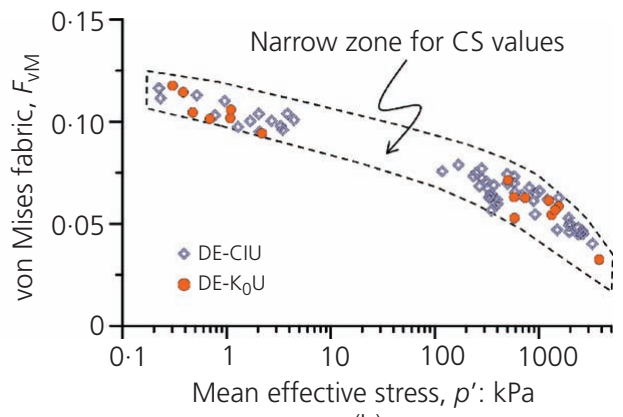

(b)

Figure 16. CS data for the micromechanical quantities - that is, (a) $C_{N}$ and (b) $F_{\mathrm{vM}}$ in relation with $p^{\prime}$ at CS 
exhibits $\mathrm{F}$ behaviour, whereas a soil state below the CSL exhibits NF behaviour. A soil state with respect to CSL can be presented by a state index. One of the widely used state indices is the state parameter $(\psi)$. Been and Jefferies (1985) defined $\psi$ as the difference between the current $e$ and the corresponding $e$ on CSL at the same $p^{\prime}$. A positive $\psi$ - that is, $e$ above CSL - exhibits $\mathrm{F}$ behaviour, whereas a negative $\psi$ - that is, $e$ below CSL - exhibits $\mathrm{NF}$ behaviour. The relation between the state parameter $(\psi)$ and characteristic features on undrained behaviour are explored in the following subsection.

\section{Relationship between state parameter $(\psi)$ and $\eta_{\mathrm{IS}}$}

The $\eta_{\text {IS }}$ and $\psi_{0}$ data points for triaxial testing after $K_{0}$ and isotropic consolidations showed a good relation, where $\eta_{\text {IS }}$ decreased with increasing $\psi_{0}$ (see Figure 17(a)). The overall trend is consistent with earlier studies for isotropic consolidated sands (Baki et al., 2012; Imam et al., 2002; Rahman and Lo, 2012; Rahman et al., 2014b; Yang, 2002). The best-fit line in this study has an RMSD of $0 \cdot 100$. However, one may notice that the $\eta_{\text {IS }}$ data points for $K_{0}$ consolidation were slightly higher than those for isotropic consolidation for higher $\psi_{0}$. This behaviour was clearly observed for the $\eta_{\mathrm{IS}}-\psi_{0}$ relation in DEM simulation - that is, $\eta_{\mathrm{IS}}$ for $K_{0}$ consolidation was significantly higher than that for isotropic consolidation for higher $\psi_{0}$ (RMSDs for the relations after isotropic and $K_{0}$ consolidations are 0.313 and 0.084 , respectively), as shown in Figure 17(b). The unique relationship between $C_{\mathrm{N}}$ at $\eta_{\mathrm{IS}}$ and $\psi_{0}$ with RMSD of 0.364 is presented in Figure $17(\mathrm{c})$, which suggests that the difference between $\eta_{\mathrm{IS}}-\psi_{0}$ relations for $K_{0}$ and isotropic consolidations are not dependent on $C_{\mathrm{N}}$. The $F_{\mathrm{vM}}$ and $\psi_{0}$ data points are presented in Figure $17(\mathrm{~d})$, which shows that $F_{\mathrm{vM}}-\psi_{0}$ for $K_{0}$ consolidation was significantly higher than that for isotropic consolidation for higher $\psi_{0}$ (RMSDs for the relations after isotropic and $K_{0}$ consolidations are 0.021 and $0 \cdot 010$, respectively). This is similar to macromechanical behaviour - that is, the $\eta_{\mathrm{IS}}-\psi_{0}$ relation in Figure $17(\mathrm{~b})$. This again suggests that the fabric quantity $\left(F_{\mathrm{vM}}\right)$ may represent the macromechanical behaviour better than the number of contacts $\left(C_{\mathrm{N}}\right)$.

\section{Relationship between state parameter $(\psi)$ and $\eta_{\mathrm{PT}}$}

Figure 18(a) shows that $\eta$ at the PT state $\left(\eta_{\mathrm{PT}}\right)$ form a unique relationship with $\psi_{0}$ in the $\eta_{\mathrm{PT}}-\psi_{0}$ space for both isotropic and $K_{0}$ triaxial experiments. The best-fit trend has an RMSD of $0 \cdot 117$. One may recall that these data exhibited separate trends in the $\eta_{\mathrm{PT}}-D_{\mathrm{r}}$ space in Figure 10(a) for isotropic and $K_{0}$-consolidated specimens. It appeared that $\psi_{0}$, which captures the effect of $e$ and $p^{\prime}$, is a better state index than $D_{\mathrm{r}}$. Figure $18(\mathrm{~b})$ also shows the unique relationship between $\eta_{\mathrm{PT}}$ and $\psi_{0}$ for both DEM isotropic and $K_{0}$ simulations. The best-fit trend has an RMSD of 0.081 . However, one may note that $\eta_{\mathrm{PT}}$ increased with $\psi_{0}$ for triaxial data, whereas $\eta_{\mathrm{PT}}$ decreased with $\psi_{0}$ for DEM data. While these are observed behaviours from this study, authors were cautious to draw a general conclusion that triaxial data are more reliable/ acceptable than DEM. This is because $(a)$ both triaxial and DEM simulations did not show a clear knee on the ESP at $\mathrm{d} p^{\prime}=0$, and an alternative approach of $\mathrm{d} \Delta u=0$ was used to identify the PT

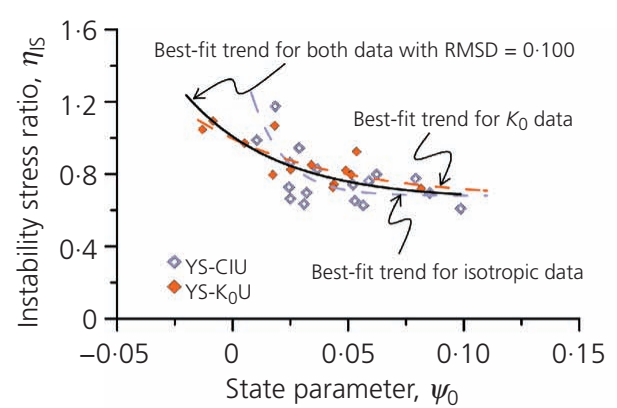

(a)

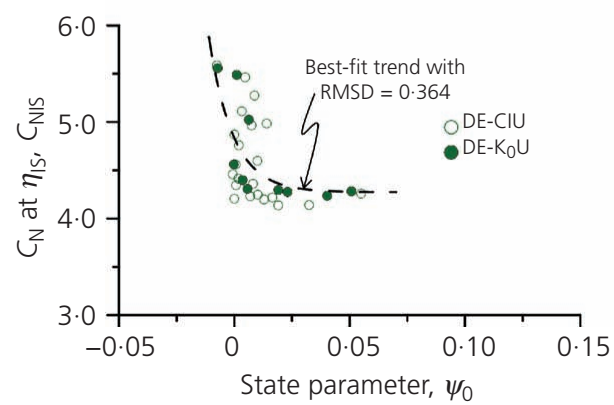

(c)

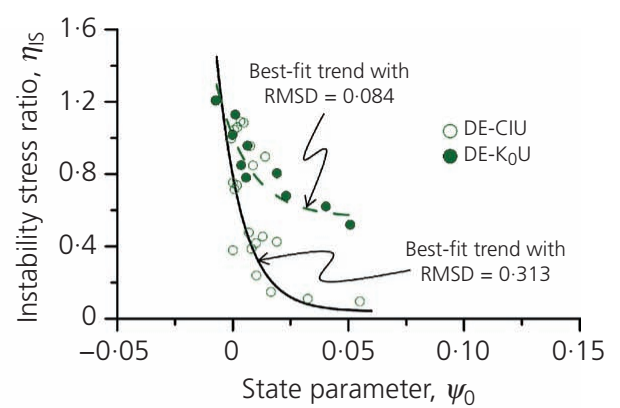

(b)

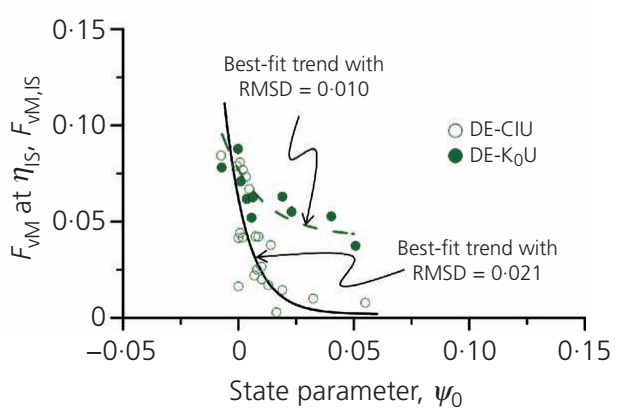

(d)

Figure 17. Relationship for $\eta_{\mathrm{IS}}$ and micromechanical quantities $\left(C_{\mathrm{N}}\right.$ and $\left.F_{\mathrm{VM}}\right)$ at $\eta_{\mathrm{IS}}$ with $\psi_{0}$ for isotropic and $K_{0}$ consolidations (a) in the $\eta_{\mathrm{IS}}-\psi_{0}$ space (triaxial tests), (b) $\eta_{\mathrm{IS}}-\psi_{0}$ space (DEM), (c) in the $C_{\mathrm{IS}}-\psi_{0}$ space (DEM) and (d) in the $F_{\mathrm{vM}}-\psi_{0}$ space (DEM) 


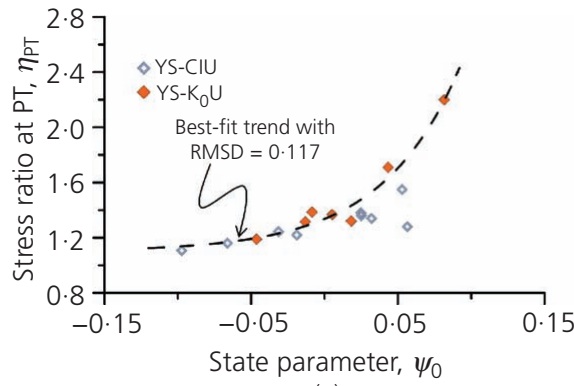

(a)

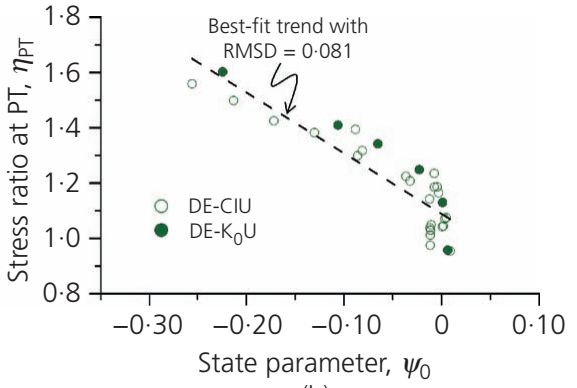

(b)

Figure 18. Relationship between $\eta_{\mathrm{PT}}$ and $\psi_{0}$ for both (a) experiments and (b) DEM simulations

state; (b) Zhang et al.'s (2018) triaxial data also show a similar trend as observed for DEM simulation. Although the authors suggest further study on the shape of $\eta_{\mathrm{PT}}-\psi_{0}$ curve, $\psi$ appeared as a better state of soil.

\section{Relationship between state parameter $(\psi)$ and $u_{\mathrm{F}}$}

The $u_{\mathrm{F}}-\psi_{0}$ relations for triaxial tests after isotropic and $K_{0}$ consolidations are presented in Figure 19(a), which shows that $u_{\mathrm{F}}$ increased with $\psi_{0}$. These data were not dependent on consolidation type. The best-fit line for these data has an RMSDs of $0 \cdot 280$. The $u_{\mathrm{F}}-\psi_{0}$ relations for DEM simulations of isotropic and $K_{0}$ consolidations are presented in Figure 19(b). Unlike for the triaxial tests, these data showed two distinct relations for isotropic and $K_{0}$ consolidations. The best-fit trend of the $u_{\mathrm{F}}-\psi_{0}$ relation for isotropic consolidation has an RMSD of 0.046 and the best-fit line for $K_{0}$ consolidation has an RMSD of $0 \cdot 004$.

\section{Conclusions}

This study combined triaxial tests on YS sand and 3D DEM cubical assembly consisting of ellipsoids under triaxial condition to investigate the effect of consolidation condition on the overall undrained behaviour and its characteristic features. Both density indices and the CSSM framework were used to develop the correlations for characteristic features of undrained behaviour (often referred to as macromechanical behaviour). The micromechanical measures such as coordination number $\left(C_{\mathrm{N}}\right)$ and fabric anisotropy $\left(F_{\mathrm{vM}}\right)$ were evaluated to understand how the micromechanical behaviour affect the macromechanical behaviour. The major findings from this study are listed in the following.

(a) For the same preconsolidation void ratio (e), the consolidation paths have a significant influence on the compressibility and post-consolidation void ratio $\left(e_{0}\right)$ for both triaxial and DEM simulations. The $K_{0}$ consolidation path achieved higher compression than that of corresponding isotropic consolidation path. The DEM simulation showed that for isotropic loading - that is, $\sigma_{1}^{\prime}=\sigma_{2}^{\prime}=\sigma_{3}^{\prime}$ - the $C_{\mathrm{N}}$ increased with $\sigma_{1}^{\prime}$ to achieve a stable state and exhibited lower compressibility, whereas $C_{\mathrm{N}}$ initially decreased with $\sigma_{1}^{\prime}$ for $K_{0}$ consolidation, which may have contributed to higher compressibility. Similarly, the fabric anisotropy $\left(F_{\mathrm{vM}}\right)$ evolved significantly during $K_{0}$ consolidation, whereas $F_{\mathrm{vM}}$ reduced during isotropic consolidation.

(b) For loose specimen, the instability or static liquefaction was triggered just after peak deviatoric stress $\left(q_{\text {peak }}\right)$ at instability stress ratio $\left(\eta_{\mathrm{IS}}\right)$. The $K_{0}$-consolidated triaxial test reached the triggering of static liquefaction - that is, $\eta_{\mathrm{IS}}$ at a much smaller deviatoric strain $\left(\varepsilon_{\mathrm{q}}=0.5 \%\right)$ than the deviatoric strain isotropic consolidated tests $\left(\varepsilon_{\mathrm{q}}=2-3 \%\right)$. A similar behaviour was observed for the ESP in the DEM simulation. However, there was no conclusive evidence from the DEM simulation

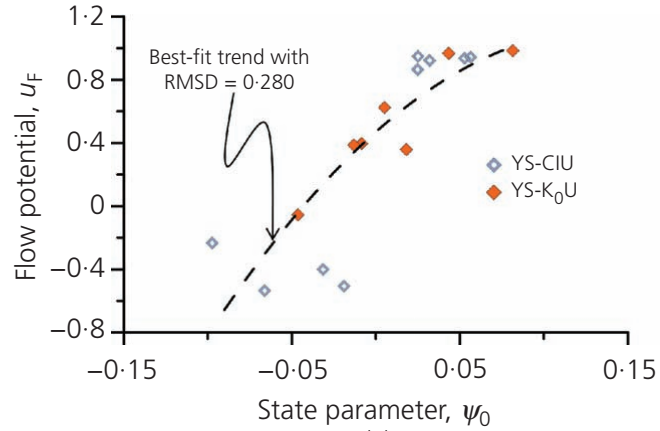

(a)

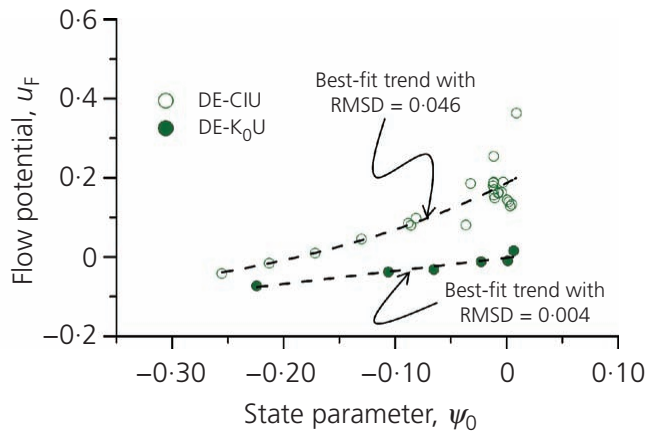

(b)

Figure 19. Relationship between $u_{\mathrm{F}}$ and $\psi_{0}$ for both (a) experiments and (b) DEM simulations 
that static liquefaction would trigger at a much smaller $\varepsilon_{\mathrm{q}}$ for $K_{0}$ consolidation than isotropic consolidation.

(c) For a dense specimen, the ESP for both triaxial and DEM simulations after $K_{0}$ and isotropic consolidations reached critical state stress ratio $(M)$. However, the ESP for DEM simulation rose above the $M$-line and then turned back to $M$ towards the end of the simulation. This behaviour is not very common for experimental studies.

(d) The $\eta_{\text {IS }}$ for loose specimen increases with relative density $\left(D_{\mathrm{r}}\right)$ for triaxial tests. Similarly, $\eta_{\mathrm{IS}}$ increased with density index $\left(D_{\mathrm{I}}\right)$ for DEM simulation. The trend was not dependent on $K_{0}$ or isotropic consolidation for both triaxial and DEM simulations. The micromechanical measures - for example, $C_{\mathrm{N}}$ and $F_{\mathrm{vM}}$ at instability - also increased with $D_{\mathrm{I}}$. Similarly, the characteristic features of the PT state also showed correlations with $D_{\mathrm{r}}$ and $D_{\mathrm{I}}$ for triaxial and DEM simulations, respectively.

(e) The critical state lines (CSLs) for YS sand were different in the $e-\log \left(p^{\prime}\right)$ space for isotropic and $K_{0}$ consolidations, where the CSL of $K_{0}$ data was higher than that of isotropic data. However, the CSL for DEM simulation for isotropic and $K_{0}$ consolidations was unique in the $e-\log \left(p^{\prime}\right)$ space. The micromechanical measures - for example, $C_{\mathrm{N}}$ and $F_{\mathrm{vM}}$ at $\mathrm{CS}-$ also showed a unique relation with $p^{\prime}$.

(f) The $\eta_{\mathrm{IS}}$ for loose specimen decreased with $\psi_{0}$ for both experiments and DEM simulations. However, the $\eta_{\mathrm{IS}}-\psi_{0}$ relation was different for isotropic and $K_{0}$ consolidation types. The unique relation was observed between $C_{\mathrm{NIS}}$ and $\psi_{0}$ irrespective of consolidation type. The $F_{\mathrm{vM}}-\psi_{0}$ relation was dependent on the consolidation type as observed for the $\eta_{\mathrm{IS}}-\psi_{0}$ relation. This suggests that the difference in the $\eta_{\mathrm{IS}}-\psi_{0}$ relation for different consolidation was not due to the change of $C_{\mathrm{NIS}}$ but for $F_{\mathrm{vM}}$.

(g) The $\eta_{\mathrm{IS}}$ and $u_{\mathrm{F}}$ showed good correlation with density indices $\left(D_{\mathrm{r}}\right.$ and $\left.D_{\mathrm{I}}\right)$ and $\psi_{0}$.

This study was based on the experimental data for YS sand and DEM simulations of the 3D cubical assembly of ellipsoid particles with linear contact model. There were assumptions made on estimating PT states, extrapolation for CS and others. Therefore, reader should be cautious in generalising the outcome of this article.

\section{Acknowledgements}

The authors would like acknowledge Professor Matthew R. Kuhn of University of Portland, USA, for his discrete-element method software Oval. The second and third author would like to acknowledge the financial support of the University Presidents Scholarship and the University of South Australia Postgraduate Research Award from University of South Australia.

\section{REFERENCES}

Alarcon-Guzman A, Leonards GA and Chameau JL (1988) Undrained monotonic and cyclic strength of sand. Journal of Geotechnical Engineering 114(10): 1089-1109, https://doi.org/10.1061/(ASCE) 0733-9410(1988)114:10(1089).
ASTM (2007) D 698: Standard test methods for laboratory compaction characteristics of soil using standard effort. ASTM International, West Conshohocken, PA, USA.

ASTM (2016) D 4253: Standard test methods for maximum index density and unit weight of soils using a vibratory table. ASTM International, West Conshohocken, PA, USA.

Baki MA, Rahman M, Lo S and Gnanendran C (2012) Linkage between static and cyclic liquefaction of loose sand with a range of fines contents. Canadian Geotechnical Journal 49(8): 891-906, https://doi. org/10.1139/t2012-045.

Baki MAL, Rahman MM and Lo SR (2014) Predicting onset of cyclic instability of loose sand with fines using instability curves. Soil Dynamics and Earthquake Engineering 61-62: 140-151, https://doi.org/10.1016/j.soildyn.2014.02.007.

Been K and Jefferies MG (1985) A state parameter for sands. Géotechnique 35(2): 99-112, https://doi.org/10.1680/geot.1985.35.2.99.

Bobei DC and Lo SR (2005) Reverse behaviour and critical state of sand with small amount of fines. In The Proceedings of the 16th International Conference on Soil Mechanics and Geotechnical Engineering (16ICSMGE) (Organising Committee of 16th ICSMGE (eds)). Millpress Science, Rotterdam, the Netherlands, pp. 475-478.

Bobei DC, Lo SR, Wanatowski D, Gnanendran CT and Rahman MM (2009) A modified state parameter for characterizing static liquefaction of sand with fines. Canadian Geotechnical Journal 46(3): 281-295, https://doi.org/10.1139/T08-122.

Bobei DC, Wanatowski D, Rahman MM, Lo SR and Gnanendran CT (2013) The effect of drained pre-shearing on the undrained behaviour of loose sand with a small amount of fines. Acta Geotechnica 8(3): 311-322, https://doi.org/10.1007/s11440-012-0195-2.

Butterfield R and Marchi M (2017) The compressibility of natural and reconstituted marine clays. Geotechnical Research 4(3): 172-177, https://doi.org/10.1680/jgere.17.00010.

Carrera A, Coop M and Lancellotta R (2011) Influence of grading on the mechanical behaviour of stava tailings. Géotechnique 61(11): 935-946, https://doi.org/10.1680/geot.9.P.009.

Chu J, Lo SR and Lee IK (1993) Instability of granular soils under strain path testing. Journal of Geotechnical Engineering 119(5): 874-892, https://doi.org/10.1061/(ASCE)0733-9410(1993)119:5(874).

Chu J, Wanatowski D, Leong WK, Loke WL and He J (2015) Instability of dilative sand. Geotechnical Research 2(1): 35-48, https://doi.org/ 10.1680/gr.14.00015.

da Cruz F, Emam S, Prochnow M, Roux JN and Chevoir F (2005) Rheophysics of dense granular materials: discrete simulation of plane shear flows. Physical Review E 72(2): 021309, https://doi.org/10.1103/ PhysRevE.72.021309.

Dafalias YF (2016) Must critical state theory be revisited to include fabric effects? Acta Geotechnica 11(3): 479-491, https://doi.org/10.1007/ s11440-016-0441-0.

Finno RJ and Rechenmacher AL (2003) Effects of consolidation history on critical state of sand. Journal of Geotechnical and Geoenvironmental Engineering 129(4): 350-360, https://doi.org/10.1061/(ASCE)10900241(2003)129:4(350).

Fourie $A B$ and Tshabalala $L$ (2005) Initiation of static liquefaction and the role of K0 consolidation. Canadian Geotechnical Journal 42(3): 892-906, https://doi.org/10.1139/t05-026.

Goudarzy M, Rahemi N, Rahman MM and Schanz T (2017) Predicting the maximum shear modulus of sands containing non-plastic fines. Journal of Geotechnical and Geoenvironmental Engineering 143(9): 06017013, https://doi.org/10.1061/(ASCE)GT.1943-5606.0001760.

Gu X, Huang M and Qian J (2014) DEM investigation on the evolution of microstructure in granular soils under shearing. Granular Matter 16(1): 91-106, https://doi.org/10.1007/s10035-013-0467-z.

Guo N and Zhao J (2013) The signature of shear-induced anisotropy in granular media. Computers and Geotechnics 47: 1-15, https://doi.org/10.1016/j.compgeo.2012.07.002. 
Huang X, O'Sullivan C, Hanley K and Kwok C (2014) Discrete-element method analysis of the state parameter. Géotechnique 64(12): 954-965, https://doi.org/10.1680/geot.14.P.013.

Imam SMR, Morgenstern NR, Robertson PK and Chan DH (2002) Yielding and flow liquefaction of loose sand. Soils and Foundations 42(3): 19-31, https://doi.org/10.3208/sandf.42.3_19.

Ishihara K (1993) Liquefaction and flow failure during earthquakes. Géotechnique 43(3): 351-415, https://doi.org/10.1680/geot.1993.43.3.351.

Ishihara K, Tatsuoka F and Yasuda S (1975) Undrained deformation and liquefaction of sand under cyclic stresses. Soils and Foundations 15(1): 29-44, https://doi.org/10.3208/sandf1972.15.29.

Jaky J (1944) The coefficient of earth pressure at rest. Journal of the Society of Hungarian Architects and Engineers 78(22): 355-358.

Jefferies M, Shuttle D and Been K (2015) Principal stress rotation as cause of cyclic mobility. Geotechnical Research 2(2): 66-96, https://doi.org/10.1680/jgere.15.00002.

Kato S, Ishihara K and Towhata I (2001) Undrained shear characteristics of saturated sand under anisotropic consolidation. Soils and Foundations 41(1): 1-11, https://doi.org/10.3208/sandf.41.1.

Kuhn MR (2006) OVAL and OVALPLOT: Programs for Analyzing Dense Particle Assemblies with the Discrete Element Method. University of Portland, Portland, OR, USA.

Kuhn MR (2016) The critical state of granular media: convergence, stationarity and disorder. Géotechnique 66(11): 902-909, https://doi. org/10.1680/jgeot.16.P.008.

Ladd RS (1978) Preparing test specimens using undercompaction. Geotechnical Testing Journal 1(1): 13-23, https://doi.org/10.1520/ GTJ10364J.

Lade PV and Ibsen LB (1997) A study of the phase transformation and characteristic lines of sand. Proceedings of Deformation and Progressive Failure in Geomechanics, Nagoya, Japan, pp. 353-358.

Li XS and Dafalias YF (2000) Dilatancy for cohesionless soils. Géotechnique 50(4): 449-460, https://doi.org/10.1680/geot.2000.50.4.449.

Li XS and Dafalias YF (2012) Anisotropic critical state theory: role of fabric. Journal of Engineering Mechanics 138(3): 263-275, https://doi.org/10.1061/(ASCE)EM.1943-7889.0000324.

Lo SR and Wardani SPR (2002) Strength and dilatancy of a silt stabilized by cement and fly ash mixture. Canadian Geotechnical Journal 39(1): 77-89, https://doi.org/10.1139/t01-062.

Lo SR, Rahman MM and Bobei DC (2010) Limited flow behaviour of sand with fines under monotonic and cyclic loading. Geomechanics and Geoengineering 5(1): 15-25, https://doi.org/10.1080/17486020 903452709.

Manzari MT and Dafalias YF (1997) A critical state two-surface plasticity model for sands. Géotechnique 47(2): 255-272, https://doi.org/ 10.1680/geot.1997.47.2.255.

Menzies BK (1988) A computer controlled hydraulic triaxial testing system. In Advanced Triaxial Testing of Soil and Rock (Donaghe RT, Chaney RC and Silver ML (eds)). ASTM International, West Conshohocken, PA, USA, pp. 82-94.

Mohamad R and Dobry R (1986) Undrained monotonic and cyclic triaxial strength of sand. Journal of Geotechnical Engineering 112(10): 941-958, https://doi.org/10.1061/(ASCE)0733-9410(1986)112:10 (941).

Murthy TG, Loukidis D, Carraro JAH, Prezzi M and Salgado R (2007) Undrained monotonic response of clean and silty sands. Géotechnique 57(3): 273-288, https://doi.org/10.1680/geot.2007.57.3.273.

$\mathrm{Ng} T$ (2006) Input parameters of discrete element methods. Journal of Engineering Mechanics 132(7): 723-729, https://doi.org/10.1061/ (ASCE)0733-9399(2006)132:7(723).

Nguyen HBK and Rahman MM (2017) The role of micro-mechanics on the consolidation history of granular materials. Australian Geomechanics Journal 52(3): 27-35.

Nguyen HBK, Rahman MM, Cameron DA and Fourie AB (2015) The effect of consolidation path on undrained behaviour of sand - a DEM approach.
In Proceedings of Computer Methods and Recent Advances in Geomechanics (Oka F, Murakami A, Uzuoka R and Kimoto S (eds)). CRC Press, Boca Raton, FL, USA, pp. 175-180, https://doi.org/10. 1201/b17435-27.

Nguyen HBK, Rahman MM and Fourie AB (2017) Undrained behaviour of granular material and the role of fabric in isotropic and $\mathrm{K} 0$ consolidations: DEM approach. Géotechnique 67(2): 153-167, https://doi.org/10.1680/jgeot.15.P.234.

Nguyen HBK, Rahman MM and Fourie AB (2018) Characteristic behaviour of drained and undrained triaxial tests: a DEM study. Journal of Geotechnical and Geoenvironmental Engineering. in press.

Perez JCL, Kwok CY, O'Sullivan C, Huang X and Hanley KJ (2016) Exploring the micro-mechanics of triaxial instability in granular materials. Géotechnique 66(9): 725-740, https://doi.org/10.1680/jgeot. 15.P.206.

Rabbi ATMZ, Rahman MM and Cameron DA (2018) Undrained behavior of silty sand and the role of isotropic and $K_{0}$ consolidation. Journal of Geotechnical and Geoenvironmental Engineering 144(4): 04018014, https://doi.org/10.1061/(ASCE)GT.1943-5606.0001859.

Rahman MM (2009) Modelling the Influence of Fines on Liquefaction Behaviour. PhD thesis, University of New South Wales at Australian Defence Force Academy, Canberra, Australia.

Rahman MM and Lo SR (2012) Predicting the onset of static liquefaction of loose sand with fines. Journal of Geotechnical and Geoenvironmental Engineering 138(8): 1037-1041, https://doi.org/ 10.1061/(ASCE)GT.1943-5606.0000661

Rahman MM and Lo SR (2014) Undrained behaviour of sand-fines mixtures and their state parameters. Journal of Geotechnical and Geoenvironmental Engineering 140(7): 04014036, https://doi.org/ 10.1061/(ASCE)GT.1943-5606.0001115.

Rahman MM, Lo SR and Gnanendran CT (2008) On equivalent granular void ratio and steady state behaviour of loose sand with fines. Canadian Geotechnical Journal 45(10): 1439-1456, https://doi.org/ 10.1139/T08-064.

Rahman M, Lo SC and Dafalias Y (2014a) Modelling the static liquefaction of sand with low-plasticity fines. Géotechnique 64(11): 881-894, https://doi.org/10.1680/geot.14.P.079.

Rahman M, Baki M and Lo S (2014b) Prediction of undrained monotonic and cyclic liquefaction behavior of sand with fines based on the equivalent granular state parameter. International Journal of Geomechanics 14(2): 254-266, https://doi.org/10.1061/(ASCE)GM. 1943-5622.0000316.

Rothenburg L and Bathurst RJ (1989) Analytical study of induced anisotropy in idealized granular materials. Géotechnique 39(4): 601-614, https://doi.org/10.1680/geot.1989.39.4.601.

Satake M (1982) Fabric tensor in granular materials. In Proceedings of the IUTAM Symposium on Deformations and Failure of Granular Materials 1982 (Vermeer PA and Luger HJ (eds)). Balkema, Rotterdam, the Netherlands, pp. 63-68.

Shuttle D and Jefferies M (2016) Determining silt state from CPTu. Geotechnical Research 3(3): 90-118, https://doi.org/10.1680/jgere.16. 00008

Sitharam TG and Vinod JS (2009) Critical state behaviour of granular materials from isotropic and rebounded paths: DEM simulations. Granular Matter 11(1): 33-42, https://doi.org/10.1007/s10035-0080113-3.

Sitharam T, Vinod JS and Ravishankar B (2008) Evaluation of undrained response from drained triaxial shear tests: DEM simulations and experiments. Géotechnique 58(7): 605-608, https://doi.org/10.1680/ geot.2008.58.7.605.

Sukumaran B, Leonards GA and Fox JP (1996) Discussion: Liquefaction and postliquefaction behaviour of sand. Journal of Geotechnical and Geoenvironmental Engineering 122(6): 502-503, https://doi.org/ 10.1061/(ASCE)0733-9410(1996)122:6(502) 
Geotechnical Research

Volume 5 Issue GR4
The effect of consolidation on undrained

behaviour of granular materials:

experiment and DEM simulation

Rahman, Nguyen and Rabbi
Thornton C (2000) Numerical simulations of deviatoric shear deformation of granular media. Géotechnique 50(1): 43-53, https://doi.org/10.1680/ geot.2000.50.1.43.

Wong STY, Ong DEL and Robinson RG (2017) Behaviour of MH silts with varying plasticity indices. Geotechnical Research 4(2): 118-135, https://doi.org/10.1680/jgere.17.00002.

Wood DM, Belkheir K and Liu DF (1994) Strain softening and state parameter for sand modelling. Géotechnique 44(2): 335-339, https://doi.org/10.1680/geot.1994.44.2.335.

Yamamuro JA and Lade PV (1997) Static liquefaction of very loose sands. Canadian Geotechnical Journal 34(6): 901-917, https://doi.org/ 10.1139/t97-057.

Yamamuro JA and Lade PV (1998) Steady-state concepts and static liquefaction of silty sands. Journal of Geotechnical and Geoenvironmental Engineering 124(9): 868-877, https://doi.org/ 10.1061/(ASCE)1090-0241(1998)124:9(868).

Yan W and Dong J (2011) Effect of particle grading on the response of an idealized granular assemblage. International Journal of Geomechanics 11(4): 276-285, https://doi.org/10.1061/(ASCE)GM.1943-5622.0000085.
Yang J (2002) Non-uniqueness of flow liquefaction line for loose sand. Géotechnique 52(10): 757-760, https://doi.org/10.1680/geot.2002.52. 10.757.

Yoshimine M, Ishihara K and Vargas W (1998) Effects of principal stress direction and intermediate principal stress on undrained shear behaviour of sand. Soils and Foundations 38(3): 179-188, https://doi.org/10.3208/sandf.38.3 179.

Zhang J, Lo SCR, Rahman MM and Yan J (2018) Characterizing monotonic behavior of pond ash within critical state approach Journal of Geotechnical and Geoenvironmental Engineering 144(1): 04017100, https://doi.org/10.1061/(ASCE)GT.1943-5606. 0001798 .

Zhao J and Guo N (2013) Unique critical state characteristics in granular media considering fabric anisotropy. Géotechnique 63(8): 695-704, https://doi.org/10.1680/geot.12.P.040.

Zhou W, Wu W, Ma G, Huang Y and Chang X (2017) Study of the effects of anisotropic consolidation on granular materials under complex stress paths using the DEM. Granular Matter 19(4): article 76, https://doi.org/10.1007/s10035-017-0763-0.

\section{How can you contribute?}

To discuss this paper, please submit up to 500 words to the editor at journals@ice.org.uk. Your contribution will be forwarded to the author(s) for a reply and, if considered appropriate by the editorial board, it will be published as a discussion in a future issue of the journal. 